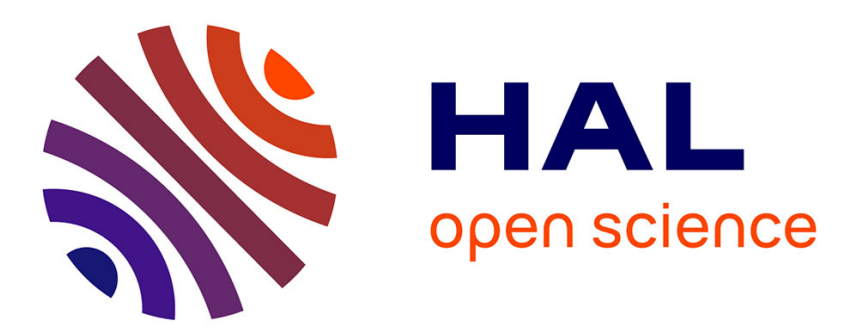

\title{
Literature review: Steady-state modelling of loop heat pipes
}

\author{
B. Siedel, V. Sartre, Frédéric Lefèvre
}

\section{To cite this version:}

B. Siedel, V. Sartre, Frédéric Lefèvre. Literature review: Steady-state modelling of loop heat pipes. Applied Thermal Engineering, 2015, 75, pp.709-723. 10.1016/j.applthermaleng.2014.10.030 . hal01286776

\section{HAL Id: hal-01286776 https://hal.science/hal-01286776}

Submitted on 11 Mar 2016

HAL is a multi-disciplinary open access archive for the deposit and dissemination of scientific research documents, whether they are published or not. The documents may come from teaching and research institutions in France or abroad, or from public or private research centers.
L'archive ouverte pluridisciplinaire HAL, est destinée au dépôt et à la diffusion de documents scientifiques de niveau recherche, publiés ou non, émanant des établissements d'enseignement et de recherche français ou étrangers, des laboratoires publics ou privés. 


\title{
Literature review: Steady-state modelling of loop heat pipes
}

\author{
Benjamin Siedel, Valérie Sartre*, Frédéric Lefèvre \\ Université de Lyon, CNRS \\ INSA-Lyon, CETHIL UMR5008, F-69621, Villeurbanne, France \\ Université Lyon 1, F-69622, Villeurbanne, France
}

\begin{abstract}
Loop heat pipes (LHPs) are efficient heat transfer systems whose operation is based on the liquid-vapour phase-change phenomenon. They use the capillary pressure generated in the porous structure to circulate the fluid from the heat source to the heat sink. In this paper, an exhaustive literature review is carried out in order to investigate the existing steady-state models of LHPs. These models can be divided into three categories: the complete numerical models, the numerical evaporator models and the analytical models. The most used models are described and compared. Finally, a synthesis summarizes all the steady-state models from the literature in a comprehensive table. The review shows the evolution of the modelling works in the past 15 years and highlights the increasing development of 3D investigations.
\end{abstract}

Keywords: Loop heat pipe, Model, Review, Steady-state, Evaporator

\section{Introduction}

Loop Heat Pipes (LHPs) are efficient heat transfer devices based on the liquid-vapour phase-change phenomenon. They provide a passive heat transfer between a heat source and a heat sink, using the capillary pressure to circulate the fluid. Compared to conventional heat pipes, LHPs offer several advantages in terms of flexibility, operation against gravity and heat transport capability.

Since their first successful applications in the aerospace industry, LHPs have gained a major interest in aeronautics and terrestrial applications. As a consequence, many experimental works have been published to provide useful data to understand the physical mechanisms governing these systems in various operating conditions (against the gravity, cyogenic applications, start-up behaviour, etc.) and to optimise their design (choice of the working fluid, material of the wick, geometry of the evaporator, etc.). At the same time, many theoretical studies have been undertaken to predict accurately the behaviour of LHPs, in particular the coupled phenomena occurring in the evaporator/reservoir structure.

Several literature reviews on LHPs are already available. $\mathrm{Ku}$ [1] presents an extensive analysis of the operating characteristics of loop heat pipes. After explaining the operating principles and the thermohydraulics of LHPs, the authors investigate the LHP behaviour (operating temperature, temperature control, start-up, hystereses, shutdown) and the effect of the evaporator mass, the elevation, the non-condensable gases and the heat losses to the am-

\footnotetext{
* Corresponding author

Email address: valerie.sartre@insa-lyon.fr (Valérie Sartre)
}

bient on the LHP operation. Several LHP designs are also discussed.

Maydanik [2] also presents a review of developments, results of theoretical analyses and tests of LHPs. The paper mainly deals with LHP designs and applications. Various types of LHPs (large, controllable, ramified, reversible, miniature) are compared and the LHPs for both spacecraft applications and electronics cooling are presented.

An extension of these works is given by Launay et al. [3]. The authors present an exhaustive review of the parameters affecting the LHP steady-state operation. An extensive analysis of the operating limits of LHPs is also provided.

A review from Ambirajan et al. [4] is also available in the literature. After explaining the fundamental concepts of the LHP behaviour, the authors discuss the construction details, the operating principles and the typical operating characteristics of LHPs. The paper also present current developments in modelling of thermohydraulics and design methodologies. The review of the modelling studies is, however, far from exhaustive and needs a further analysis.

Launay and Vallée [5] presents an exhaustive overview of the experimental studies published between 1998 and 2010. This review provides a database of experimental results and highlights some omissions in the published works that make the data difficult to use for further studies.

Recently, Maydanik et al. [6] presented a literature review of developments and tests of LHPs with flat evaporator designs. The authors discuss the various geometrical configurations (disk-shaped, rectangular, flat-oval) and the working fluids that may be used in each case. Then, the modelling works on flat evaporators are presented and the applications of such systems are discussed. 
Wang and Yang [7] carry out a review on loop heat pipes dedicated to use in solar water heating. After analysing the working principles of LHPs and discussing the existing experimental and theoretical works, the authors further investigate the opportunities of using solar water heating systems with LHPs.

No exhaustive review on LHP steady-state modelling studies exists in the literature. This paper intends to introduce a comprehensive review of the existing theoretical works on this subject that have been published since 1999 . This work should help to give a global view of the existing models in the literature and to point out their similarities and differences. It also highlights the physical mechanisms involved in LHPs that are today still not appropriately taken into account in most of the investigations.

Most of the theoretical models can be divided into three categories, corresponding to complete numerical LHP models, to precise evaporator descriptions and to analytical approaches to describe LHPs.

\section{Complete numerical LHP models}

The majority of complete numerical LHP models are based on a volume element discretisation or on electrical analogies and describe the whole device as a nodal network. The links between the nodes are represented by thermal resistances or conductances and the energy balance equation is applied to each node.

Kaya et al. [8] develop a mathematical model of a loop heat pipe based on the steady-state energy balance equations at each component of the system. A cylindrical evaporator is considered. The following main assumptions are used in the development of the model:

- The heat transfer through the wick is directed only towards the radial direction.

- The compensation chamber and the evaporator core contain both liquid and vapour phases.

- The LHP reaches steady-state for a given loop condition.

The total heat load to be dissipated $Q_{\text {in }}$ is equal to the sum of the heat rejected in the two-phase portion of the condenser (latent heat) $Q_{\mathrm{c}}$, the parasitic heat leak $Q_{\mathrm{hl}}$ and the heat losses from the vapour line to the ambient $Q_{\mathrm{vl}-\mathrm{a}}$ :

$$
Q_{\text {in }}=Q_{\mathrm{c}}+Q_{\mathrm{hl}}+Q_{\mathrm{vl}-\mathrm{a}}
$$

In the evaporator, the heat leak compensates the subcooling of the returning liquid $Q_{\mathrm{sc}}$ and the heat losses from the compensation chamber to the ambient $Q_{\text {cc-a }}$ :

$$
Q_{\mathrm{hl}}=Q_{\mathrm{sc}}+Q_{\mathrm{cc}-\mathrm{a}}
$$

To calculate the heat leak, the authors only consider conduction through the wick, which can be written as:

$$
Q_{\mathrm{hl}}=\frac{2 \pi \lambda_{\mathrm{eff}} L_{\mathrm{w}}}{\ln \left(D_{\mathrm{w}, \mathrm{o}} / D_{\mathrm{w}, \mathrm{i}}\right)} \Delta T_{\mathrm{ac}, \mathrm{w}}
$$

where $\lambda_{\text {eff }}$ is the effective thermal conductivity of the wick, $L_{\mathrm{w}}$ its length and $D_{\mathrm{w}, \mathrm{i}}$ and $D_{\mathrm{w}, \mathrm{o}}$ its inner and outer diameters, respectively. The temperature across the wick $\Delta T_{\mathrm{ac}, \mathrm{w}}$ is the difference between the local saturation temperatures caused by the total system pressure drops $\Delta P_{\text {total }}$, excluding the pressure drop in the wick structure $\Delta P_{\mathrm{w}}$ :

$$
\Delta T_{\mathrm{ac}, \mathrm{w}}=\left(\frac{\partial T}{\partial P}\right)_{\mathrm{sat}}\left(\Delta P_{\text {total }}-\Delta P_{\mathrm{w}}\right)
$$

The slope of the vapour-pressure curve $(\partial T / \partial P)_{\text {sat }}$ can be calculated using the Clausius-Clapeyron relation. The total pressure drops in the system consist of the frictional steady-state pressure drops in the vapour line $\Delta P_{\mathrm{vl}}$, the liquid line $\Delta P_{11}$, the condenser $\Delta P_{\mathrm{c}}$, a potential subcooler $\Delta P_{\mathrm{sc}}$, the bayonet $\Delta P_{\text {bay }}$, the porous structure $\Delta P_{\mathrm{w}}$ and the vapour grooves $\Delta P_{\mathrm{vgr}}$. If the LHP is not in horizontal orientation, the pressure difference associated with the gravity effects $\Delta P_{\text {grav }}$ also needs to be taken into account:

$$
\begin{aligned}
\Delta P_{\text {total }}= & \Delta P_{\mathrm{vl}}+\Delta P_{\mathrm{ll}}+\Delta P_{\mathrm{c}}+\Delta P_{\mathrm{sc}}+\Delta P_{\text {bay }}+\Delta P_{\mathrm{w}} \\
& +\Delta P_{\mathrm{vgr}}+\Delta P_{\text {grav }}
\end{aligned}
$$

The authors employ single-phase correlations to calculate all the frictional pressure drops and take into account the flow regime (laminar or turbulent) in the calculation. The relevant properties of the fluid are calculated with respect to the saturation temperature $T_{\text {sat }}$. Two distinct correlations are used to estimate the effective thermal conductivity of the wick. To determine heat losses to the ambient, the authors test either a natural convection hypothesis or a radiative hypothesis.

The two-phase heat removal in the condenser consists of two parts: heat rejection to the sink and heat loss to the ambient. The length of the two-phase flow portion in the condenser $L_{\mathrm{c}, 2 \varphi}$ is then given by:

$$
\begin{gathered}
L_{\mathrm{c}, 2 \varphi}=Q_{\mathrm{c}} \int_{x_{\mathrm{in}}}^{x_{\text {out }}} \mathrm{d} x\left[(U A / L)_{\mathrm{c}, \mathrm{s}}\left(T_{\mathrm{sat}}-T_{\text {sink }}\right)\right. \\
\left.+(U A / L)_{\mathrm{c}, \mathrm{a}}\left(T_{\mathrm{sat}}-T_{\mathrm{amb}}\right)\right]^{-1}
\end{gathered}
$$

where $(U A / L)_{\mathrm{c}, \mathrm{s}}$ and $(U A / L)_{\mathrm{c}, \mathrm{a}}$ are the thermal conductance per unit length from the surface of the condenser to the heat sink and to the ambient, respectively and $x$ is the thermodynamic quality of the flow: $x_{\text {in }}=1$ and $x_{\text {out }}=0$ if the total two-phase region is located in the condenser. $T_{\text {sink }}$ and $T_{\mathrm{amb}}$ are the temperatures of the heat sink and the ambient, respectively. The liquid temperature at the exit of the condenser is calculated by integration of the local heat balance on an elementary length of the tube $\mathrm{d} z$ :

$\dot{m} c_{\mathrm{p}, \mathrm{l}} \frac{\mathrm{d} T}{\mathrm{~d} z}=(U A / L)_{\mathrm{c}, \mathrm{a}}\left(T-T_{\mathrm{amb}}\right)+(U A / L)_{\mathrm{c}, 1}\left(T-T_{\mathrm{sink}}\right)$

where the mass flow rate $\dot{m}$ is:

$$
\dot{m}=\frac{Q_{\mathrm{c}}}{h_{\mathrm{lv}}}
$$


and $c_{\mathrm{p}, 1}$ and $h_{\mathrm{lv}}$ are the specific heat of the liquid and the enthalpy of vaporisation of the fluid, respectively.

The same method is applied for the potential subcooler and for the liquid line. The subcooling of the returning liquid is thus given by:

$$
Q_{\mathrm{sc}}=\dot{m} c_{\mathrm{p}, 1}\left(T_{\mathrm{sat}}-T_{1, \mathrm{out}}\right)
$$

where $T_{1, \text { out }}$ is the fluid temperature at the end of the liquid line. The LHP operating temperature $T_{\text {sat }}$ is then a function of $Q_{\text {in }}, T_{\text {sink }}$ and $T_{\mathrm{amb}}$. An iterative procedure is implemented until convergence is reached.

The authors compare their model to experimental data obtained with the GLAS LHP $^{1}$ and another loop developed for the Naval Research Laboratory (NRL). The predictions, for two distinct heat sink temperatures, are very close to the experimental results. At low powers, some discrepancies exist showing a need of a more precise consideration of the heat losses to the ambient.

The consideration of radial mass flow in the wick was added in a later paper, and new correlations for natural convection were also compared to better take into account heat losses to the ambient [10]. The authors state that the mathematical modelling of the LHP performance characteristics becomes more difficult as the size of the LHP decreases. Indeed, the low mass flow rates associated with the low power levels in small LHPs induce a longer dwelling time for the working fluid in the transport lines, despite smaller tube diameters. Therefore, the heat exchange with the surroundings becomes more important. Additionally, heat and mass transfer in small diameter tubes is less investigated and thus more difficult to predict. According to the authors, the differences between the measured and the calculated LHP operating temperatures are mainly attributed to the inability to predict the overall effective thermal conductance across the wick.

The 1-D steady-state model of Chuang [11] is based on the energy balance equation, thermodynamic relationships and detailed heat transfer and pressure drop calculations in the liquid, vapour and condenser lines. The model includes the pressure drops induced by the bends in both the transport lines and the condenser, the convective heat transfer between the fluid and the wall in the vapour groove and both axial and radial heat fluxes in the wick. In a horizontal configuration, pressure drops in the vapour line, in the condenser, and through the wick are found to be in the same order of magnitude, except at low heat loads for which the pressure drops due to the fluid flow in the porous structure are dominant. Moreover, heat transfer in the vapour channels induces a slight superheat (several Kelvins) at the entrance of the vapour line. This study describes extensively the LHP operation in gravity-assisted conditions. When the LHP is operated at a positive elevation (condenser located above the evaporator/reservoir,

${ }^{1}$ GLAS LHP: Geoscience Laser Altimeter System Prototype Loop Heat Pipe, purchased by the NASA in 1997 from Dynatherm Corporation [9] evaporator/reservoir in horizontal configuration), it can operate in capillary-controlled mode or gravity-controlled mode. When the operation is controlled by the capillary forces, the vapour grooves are only filled with vapour and the total mass flow rate $\dot{m}_{\text {total }}$ can directly be calculated using the heat flux dissipated by evaporation $Q_{\text {evap }}$ :

$$
\dot{m}_{\text {total }}=\dot{m}_{\mathrm{v}}=\frac{Q_{\text {evap }}}{h_{\mathrm{lv}}}
$$

where $\dot{m}_{\mathrm{v}}$ is the vapour mass flow rate in the grooves. In the gravity-controlled mode, the fluid flow in the channel becomes two-phase. The mass flow rate is therefore calculated by:

$$
\dot{m}_{\text {total }}=\dot{m}_{\mathrm{v}}+\dot{m}_{1}=\frac{Q_{\text {evap }}}{h_{\mathrm{lv}}}+\dot{m}_{\mathrm{l}}
$$

where $\dot{m}_{1}$ denotes the liquid mass flow rate forced into the vapour groove. Additionally, the pressure gain has to be taken into account in the pressure balance equation. In the gravity-controlled mode, the pressure gain from the liquid head compensates the system total pressure drops. According to the authors' results, when the heat load is low, the LHP operates in gravity-controlled mode and the total mass flow rate in the system does not change much with the heat input. The operation is then similar to that of a thermosyphon. However, for higher heat loads, evaporation across the menisci at the outer surface of the primary wick takes place and provides the additional pressure gain required by the system (capillary-controlled mode). The elevation has a great impact on the LHP operation when the heat load is low and modifies significantly the shape of the characteristic curve. Despite interesting results, heat transfer in the evaporator and the reservoir are not precisely described and the authors stress the need of a better radial heat leak model based on heat load, temperature distribution in the primary wick, orientation, properties of the primary wick and vapour quality in the evaporator core.

Adoni et al. [12] developed a mathematical model to predict thermal and hydraulic performance of an LHP, based on conservation of mass and energy in the system. The presented model is valid for several geometries (cylindrical or flat-plate evaporator, LHP or CPL). The same general method as the one previously described is implemented. Additionally, the pressure drops across the wick are calculated using the Darcyan theory and specific correlations from the works of El Hajal et al. [13] and Thome et al. [14] as well as the Friedel correlation [15] are used to calculate the two-phase heat transfer and pressure drops in the condenser.

Their model includes the consideration of hard-filling, corresponding to a reservoir full of liquid, thus not allowing a two-phase saturation equilibrium in this loop element. In that case, the energy balance equation in the LHP core (Equation 2) is solved simultaneously for the reservoir temperature and the liquid density in the reservoir. Indeed, the reservoir temperature determines both 
the subcooling of the liquid entering the condenser and the liquid density inside the reservoir. Thus, knowing the exact mass of working fluid in the system, it is possible to determine a reservoir temperature that provides at the same time enough subcooling and a two-phase length that is consistent with a flooded reservoir.

The authors conclude that hard-filling leads to an early fixed conductance mode, an increase of heat leaks and a reduction of the condensation length due to the expansion of the liquid.

A later study adds the consideration of the bayonet and presents the effect of the mass of working fluid on the LHP performance [16]. To take into account the presence of the bayonet, the authors add several nodes to the model (Figure 1).

In the evaporator core, there is a heat balance between the radial heat leak $Q_{\mathrm{hl}}$, the heat from the core to the reservoir $Q_{c, r}$ and the subcooling of the returning liquid:

$$
Q_{\mathrm{hl}}=\dot{m} c_{\mathrm{p}, 54 \mathrm{e}}\left(T_{5}-T_{4 \mathrm{e}}\right)+Q_{\mathrm{c}, \mathrm{r}}
$$

where $c_{\mathrm{p}, 54 \mathrm{e}}$ is the mean specific heat of the working fluid between the outlet of the bayonet (5) and the inlet of the core in the bayonet $(4 e) . Q_{\mathrm{c}, \mathrm{r}}$ is equal to:

$$
Q_{\mathrm{c}, \mathrm{r}}=\lambda_{\mathrm{c}, \mathrm{r}}\left(T_{5}-T_{\mathrm{r}}\right)
$$

where $\lambda_{c, r}$ is the thermal conductance between the core and the reservoir. In the reservoir, the energy balance is:

$$
Q_{\mathrm{r}, \infty}=Q_{\mathrm{b}, \mathrm{r}}+Q_{\mathrm{c}, \mathrm{r}}+Q_{\text {evap }, \mathrm{r}}
$$

where $Q_{\mathrm{r}, \infty}$ is the heat loss to the ambient, $Q_{\mathrm{b}, \mathrm{r}}$ is the heat exchange between the fluid and the bayonet in the reservoir and $Q_{\text {evap,r }}$ is the axial parasitic heat flux. The authors describe two distinct states of the reservoir. Indeed, the thermal coupling between the reservoir and the core strongly depends on the volume of working fluid inside the loop. If the height of liquid in the reservoir is such that vapour can exist in the reservoir tube and the core, then the reservoir has a good thermal and hydraulic coupling with the core. Otherwise, a bad thermal link exists. When a bayonet is present in the core, as cold liquid exits from it, the temperature of the reservoir is higher than that of the core which is subcooled. In case of a good thermal link, the vapour generated in the reservoir travels to the colder core where it condenses.

The authors also further studied the hard-filling phenomena and the influence of the bayonet on a hard-filled reservoir [17]. Their results show that the mass of working fluid and the bayonet have a significant influence on the LHP operation. With larger masses, the heat load at which hard filling occurs reduces, thus inducing a steep rise in the operating temperature. When a bayonet exists and the ambient temperature is higher than that of the heat sink, the superheat of the reservoir may lead to a deprime of the loop. Indeed, in such a case, the hard-filling leads to a steep rise of the liquid temperature in the reservoir compared to the core temperature. If the superheat is high enough, boiling incipience could occur and induce a major degradation or even the failure of the loop operation.

Bai et al. [18] also model an LHP (with cylindrical evaporator) based on energy conservation laws. Their work shows the influence of a two-layer compound wick (Figure 2) and takes into consideration the liquid-vapour shear stresses in the condenser, based on an annular flow regime and considering both phases independently. Heat transfer in the evaporator is modelled using a nodal network and applying an energy balance at each node. The various thermal conductance are estimated by the experimental data or calculated using a radial $1 \mathrm{D}$ approximation of heat and mass transfer in the wick. The description of the two-phase region in the condenser (and in the transport lines if the two-phase zone exceeds the condenser boundaries) is obtained by finite difference solutions. The vapour quality and the pressure drops are thus obtained. The transport lines are divided into several nodes, each of which representing a certain control volume, and the calculations are conducted at each node. However, longitudinal conduction in the transport lines is neglected and the thermal conductance between the evaporator wall and the liquid-vapour interface is set in accordance with experimental results. The study also describes the behaviour of a loop with a flooded reservoir (hard-filling). Under this situation, the volume expansion of the working fluid in the reservoir results in the filling of an increasing length of the condenser when the applied heat load and the operating temperature increase. The conclusions are the same as in the work of Adoni et al. [12]. The authors also conducted a parametric analysis of a cryogenic LHP based on the same model, with the addition of secondary condenser, evaporator and compensation chamber [19].

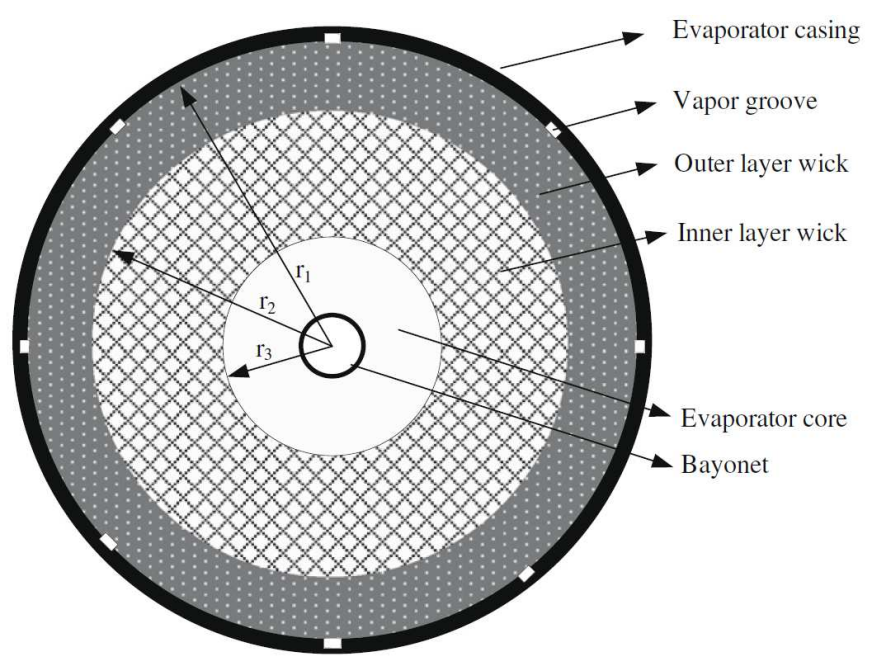

Figure 2: Schematic of the cross-section of a two-layer compound wick [18]

Singh et al. [20] present a steady-state model of an LHP with a flat disk-shaped evaporator on the basis of mass and energy conservation principles for several control vol- 


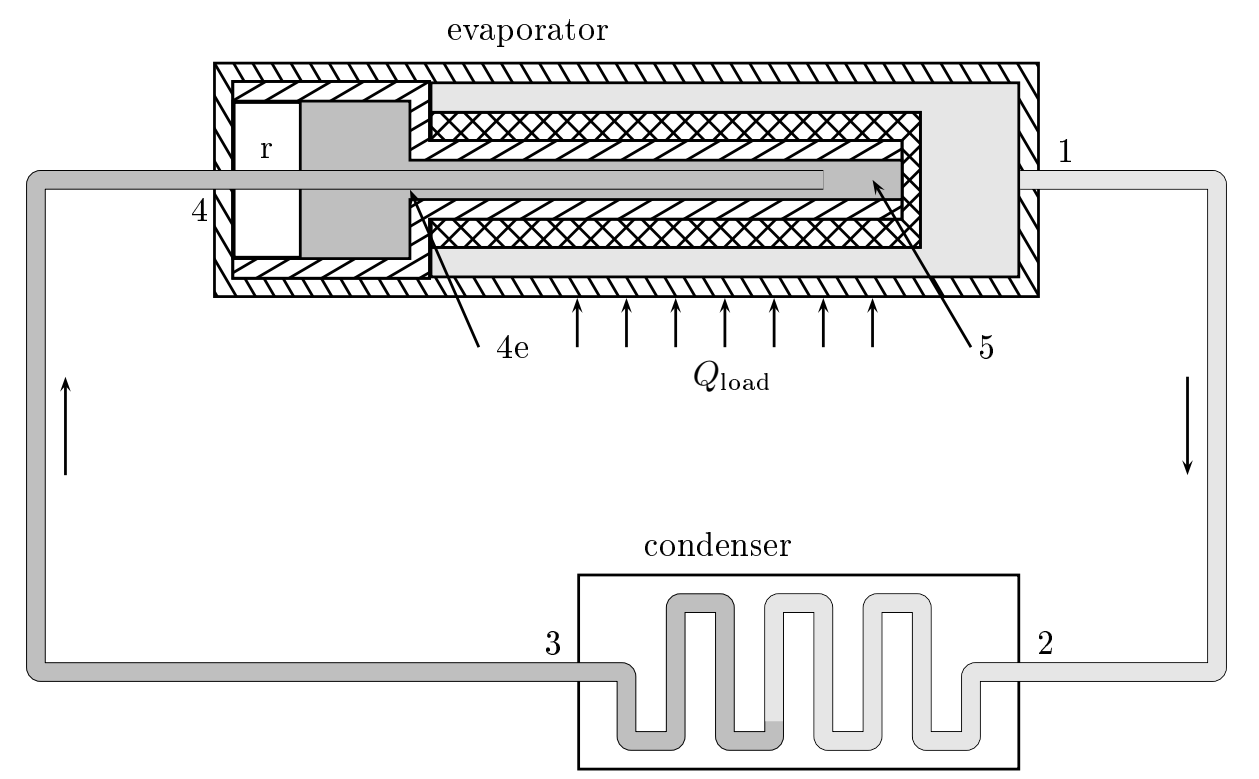

Figure 1: Schematic of an LHP with a cylindrical evaporator and a bayonet

umes. The description of the evaporator takes into account heat losses to the ambient as well as parasitic heat transfer (Figure 3). The total heat load is dissipated by the evaporation, heat losses to the ambient and the subcooling of the returning liquid. Single-phase flow correlations are used in the condenser and heat losses to the ambient are neglected. A condenser model is developed to take into account the fin-and-tube geometry of the condenser. A global description is presented, defining an overall surface efficiency of the fin array and a log mean temperature difference from the fin surface to the ambient air. The surface temperature of the fin array is considered uniform and equal to the temperature of the condenser tube. An acceptable agreement with the experimental data is found with a nickel wick. However, a rather large difference is observed between the calculated performance for a copper wick and the experimental results. According to the authors, this is probably due to the shortcoming of the model to consider accurately the heat and mass transfer inside the evaporation zone.

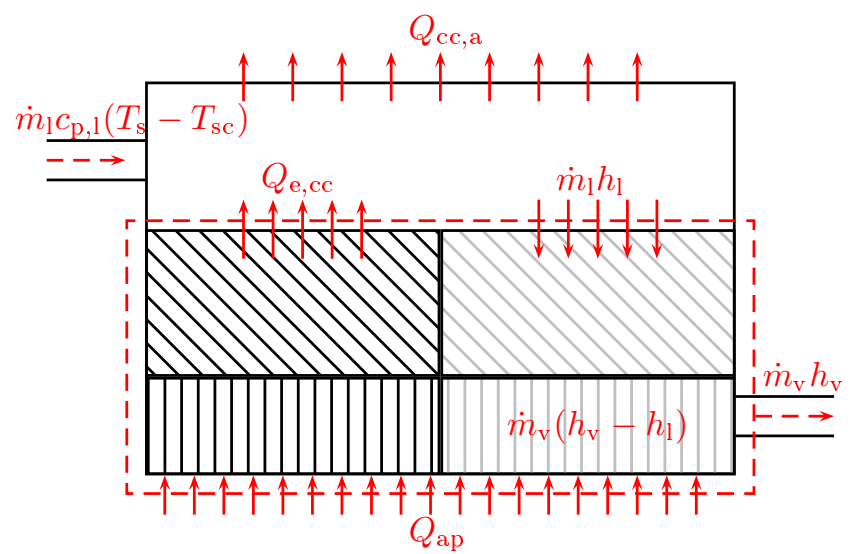

Figure 3: Energy balance on the evaporator
Rivière et al. [21] present a complete numerical model of LHP in order to study the influence of the fluid mass distribution in a loop with a flat evaporator. The model is based on a classic nodal network for the consideration of heat transfer in the evaporator/reservoir. However, the vapour grooves, the transport lines and the condenser are discretised into small elements and two energy balance equations are applied on each element, one for the solid wall and one for the fluid. Such a distinction between the wall and the fluid temperatures is the main original feature of this model (Figure 4). It enables to take into account the temperature variation in the vapour grooves and in the vapour line, as well as the longitudinal conduction through the transport line walls. Furthermore, the possible occurrence of fluid condensation in the vapour line as well as a vapour desuperheating zone in the condenser are considered. The authors show that vapour starts to condensate in the vapour line, due to heat losses to the ambient. They also investigate the influence of the transport line wall thermal conductivity and the fluid mass distribution in the LHP during operation. This model is further developed in Siedel et al. [22]. The authors combine the monodimensional discretisation of the transport lines with a $2 \mathrm{D}$ development of the heat and mass transfer in the wick and in the evaporator casing, in the case of a disk-shaped geometry. Such an improvement enables an accurate determination of the parasitic heat fluxes and the consideration of an accommodation coefficient to characterise heat transfer in the evaporation zone.

Hodot et al. [23] developed a global LHP model, combining a fine three-dimensional description of the evaporator/reservoir and a monodimensional thermo-hydraulic model of the transport lines and the condenser. The 3D heat transfer equation is solved using the OpenFOAM software and results are presented for a cylindrical geometry. 


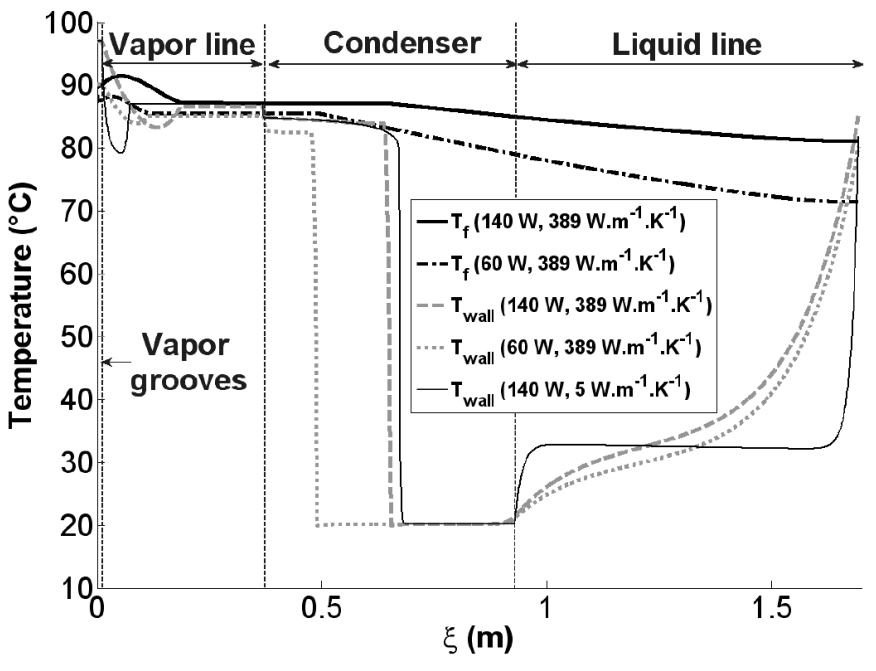

Figure 4: Fluid and wall temperatures along the LHP [21]

Convective heat transfer is taken into account inside the reservoir, in the grooves, as well as in the porous medium. The 1D nodal model of the transport lines is based on the work of Rivière et al. [21], enabling the consideration of the longitudinal conduction in the transport lines. The authors use the simulations to optimise the saddle shape design (Figure 5) and the vapour grooves number and location. Such a complete model associates a thorough modelling of heat and mass transfer in the transport lines and the condenser with a fine $3 \mathrm{D}$ thermal description of the evaporator/reservoir, thus enabling an accurate consideration of the parasitic heat losses during operation.

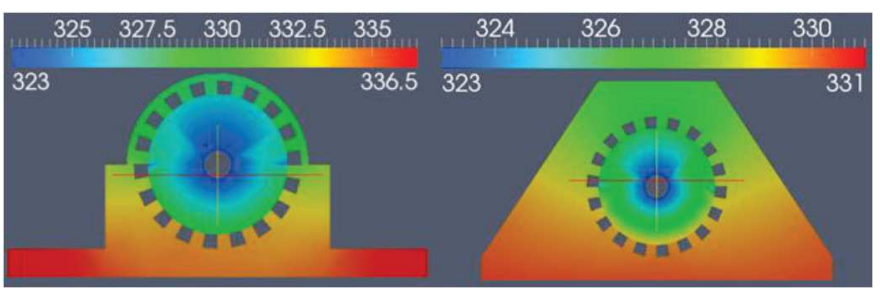

Figure 5: Optimisation of the saddle shape [23]

Several other global numerical steady-state models can be found in the literature [24-30]. They are summarised in section 5 .

\section{Numerical evaporator models}

Many numerical LHP models can be found in the literature and are useful tools for the design and optimization of LHPs as well as for a better understanding of the coupled phenomena involved in the LHP operation. However, these models are limited and their major restriction lies in an inaccurate modelling of the phenomena occurring in the evaporator/reservoir. Indeed, heat transfer inside the evaporator as well as heat losses to the ambient have a decisive influence on the loop operation, particularly at low heat loads. Therefore, heat and mass transfer between the components constituting the evaporator reservoir (the evaporator casing, the wick, the reservoir wall, the liquid pool inside the reservoir and the vapour grooves) must be evaluated accurately. These heat fluxes depend on numerous parameters: groove design, effective thermal conductivity of the wick, evaporation heat transfer, thermal conductivity of the evaporator envelope material, thermohydraulic properties of the fluid, etc. As a consequence, thorough studies have been undertaken to model heat transfer in the evaporating region, in the wick, or in the entire evaporator/reservoir.

Several theoretical analyses specifically investigate the development of a vapour zone inside the porous medium [31-36]. These studies, based on continuum models or pore-network simulations, focus on heat and mass transfer inside the wick in order to evaluate the size and the shape of a potential liquid-vapour interface inside the porous structure. Other investigations assume a porous structure that is fully saturated with liquid.

\subsection{Fully saturated wick}

A majority of the LHP models from the literature assume a complete liquid saturation of the wick and a static liquid-vapour interface at the surface of the wick in contact with the groove. In that case, the menisci providing the capillary pressure are all located in the pores at the surface of the porous structure in contact with the grooves and the wick is full of liquid.

$\mathrm{Li}$ and Peterson [37] developed a three-dimensional steady-state model of a square flat evaporator with a fully saturated wick structure. The computational domain includes the liquid bulk of the reservoir, the wick, a groove and a metallic substrate where the heat input is imposed (Figure 6). The 3D governing equations for the heat and mass transfer (continuity, Darcy and energy) are developed. A temperature boundary condition is adopted at the liquid-vapour interface, assuming a perfect evaporation rate. Furthermore, no thermal resistance is taken into account for the contact between the envelope and the wick. In order to expedite the convergence of the calculations, a line-by-line iteration and a Tridiagonal Matrix Algorithm along with a Thomas algorithm solver, and successive under-relaxation iterative methods are used to obtained the three-dimensional temperature distribution. The temperature and pressure distributions in the wick are discussed and the velocity field is investigated. The highest heat flux occurs in the wick-fin-groove corner, confirming the results of Demidov and Yatsenko [38]. Furthermore, the results show that the temperature difference is not significant along the axial direction of the groove. Thus, a two-dimensional assumption is acceptable in the modelling of the evaporator.

Zhang et al. [39] also developed a 3D model of a flat evaporator of an LHP. However, in that case, the reservoir is adjacent to the wick. Thus, the liquid flow entering the 


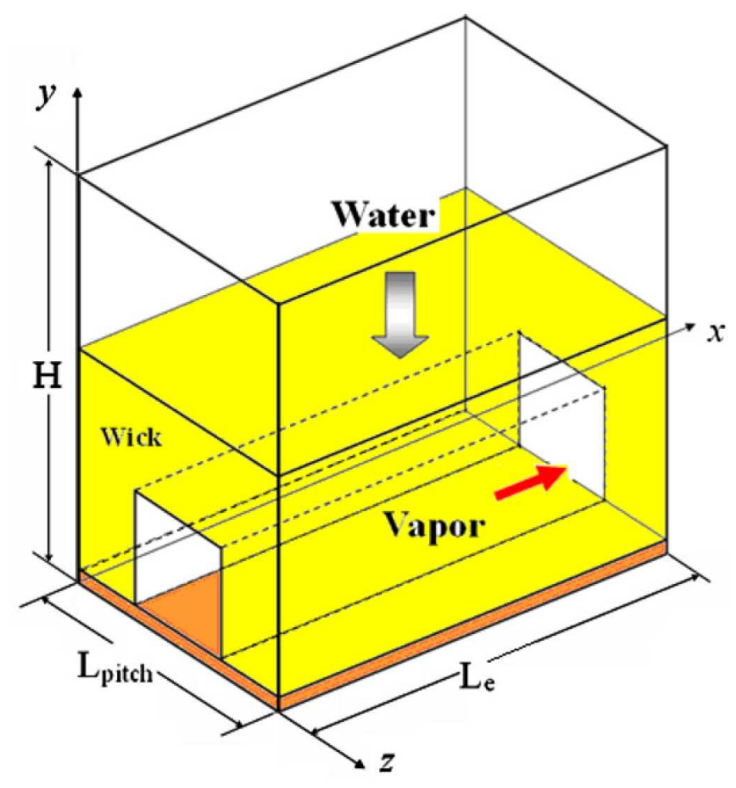

Figure 6: View of the computational domain [37]

wick is perpendicular to the heat flux imposed at the evaporator wall. The computational domain is approximately the same as in the work of Li and Peterson [37] (Figure 7). The wick is considered to be fully saturated with liquid. The fluid flow in the wick and in the groove are determined based on the equations of continuity, energy, momentum and Darcy. Heat conduction is also computed in the wall region. No heat losses to the ambient nor from the wall to the reservoir are considered. The boundary conditions for the wick region are the reservoir temperature on one side and the saturation temperature of the vapour groove at the liquid-vapour interface. The thermal contact between the wall and the wick is considered perfect. A finite volume method is introduced to solve the problem.

The flow and temperature fields in the wick and the structural optimisation of the evaporator (location and shape of the grooves) are discussed (Figure 8). The results show that the temperature at the top of the wall increases smoothly in the axial direction of the groove. Due to the effect of evaporation, the temperature is higher in the wick than at the interface between the wick and the vapour groove. The liquid flowing through the wick is superheated before reaching the evaporation zone. The pressure drop induced by the flow in the wick is only of $129 \mathrm{~Pa}$ when the heat load is equal to $80 \mathrm{~W}\left(10 \mathrm{~W} \cdot \mathrm{cm}^{-2}\right)$. An investigation is also made about the location and the geometrical characteristics of the vapour grooves. Two types of evaporators are compared: one with the vapour grooves machined inside the wick (Figure $8 \mathrm{~b}$ ) and another with the grooves inside the wall (Figure $8 \mathrm{c}$ ). When the groove is located inside the wall, the evaporating interface is only located at the bottom of the vapour groove, which results in larger temperature gradients in the wick, a higher superheat of the liquid inside the capillary structure and a higher temperature of the evaporator heating wall. The a
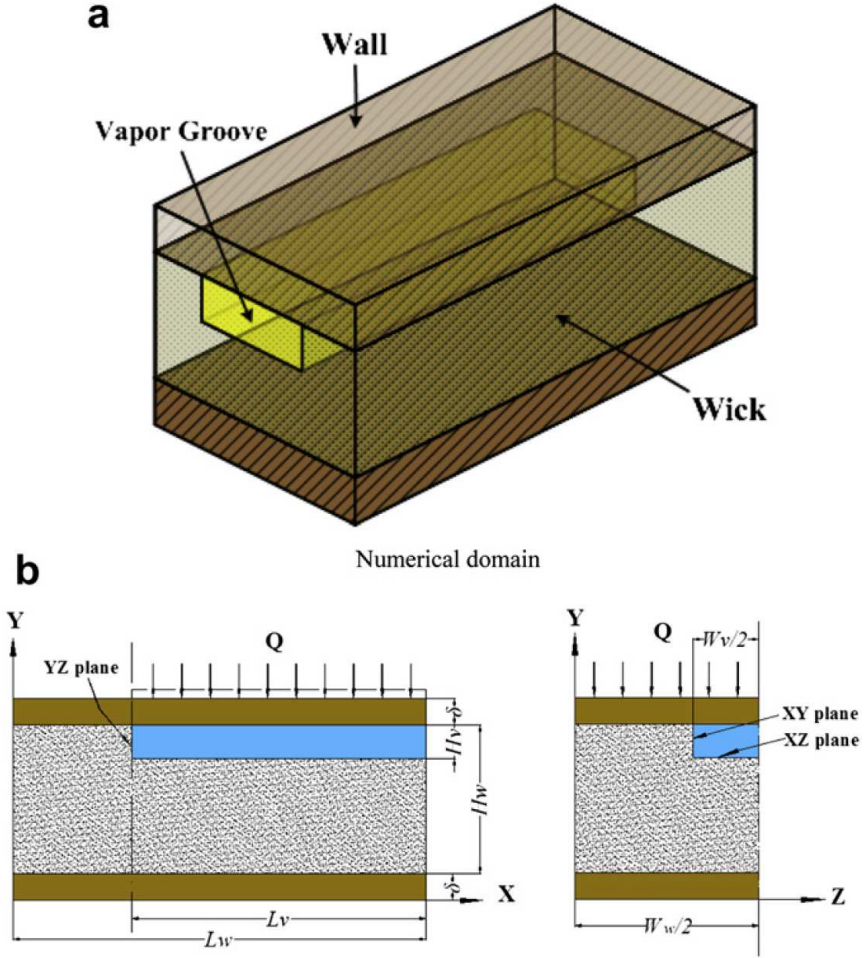

coordinate system

Figure 7: Numerical domain and coordinate system [39]

authors also conclude that the best results are achieved with square grooves (ratio height-width equal to 1 ) and with a width ratio fin-groove ranging from 0.5 to 1 .

Chernysheva and Maydanik [40] present a 3D mathematical model of a complete flat LHP evaporator with the reservoir adjacent to the porous structure. All the main structural elements of the evaporator/reservoir are included in the model: body, wick, vapour grooves, barrier layer and compensation chamber (Figure 9). The threedimensional heat equation is solved for the entire evaporator. The authors consider a finite evaporation heat transfer, thermal contact resistance between the wick and the body and the drying of the wick surface, based on the nucleation theory. If the local liquid superheat in the pores is larger than a calculated nucleation superheat, the wick surface is considered dry and no evaporation occurs at this particular spot. Due to the agitation ensured by the liquid that arrives from the liquid line, the fluid inside the compensation chamber is considered at a uniform temperature. A finite difference method is computed to solve numerically the problem. The model adequately describes thermal processes in the evaporator and the specific character of a one-sided heat load supply. The authors obtain the 3D temperature field in the entire evaporator as well as the velocity fields in the grooves (Figure 9). The results show a nonuniformity of the evaporation rate in the entire active zone. Indeed, there are low-evaporation zones owing to the insufficient heating of the peripheral sections of 


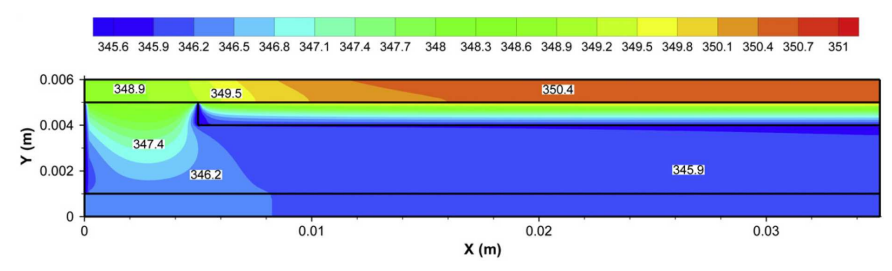

(a) Temperature contours along the axial direction

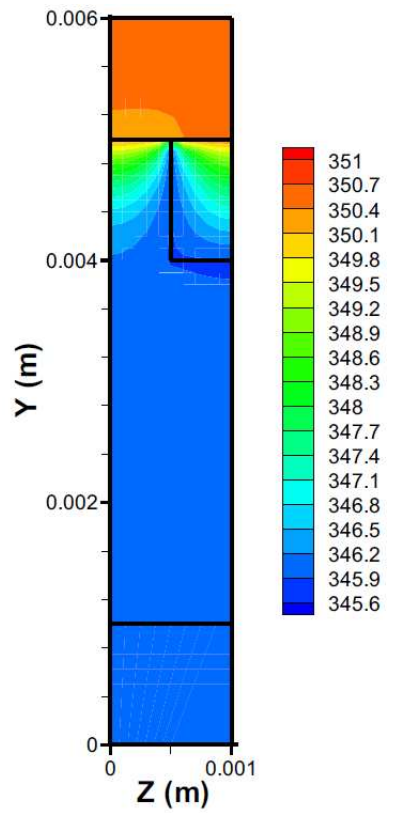

(b) Temperature field with (c) Temperature field with grooves in the wick

Figure 8: Temperature field in the flat evaporator [39]

the evaporator. The vapour grooves located in the centre of the active zone contribute mainly to the evaporation process. However, at high heat fluxes, large superheats and a potential drying of the wick may lead to a larger activation of the evaporation processes in the peripheral sections. About $90 \%$ of the total heat load is dissipated through evaporation.

Chernysheva and Maydanik [41] further discuss the temperature distribution in the evaporator and different phases of the wick drying process for uniform and concentrated heating, based on the same model. A uniform heating means that the whole active zone is heated whereas in the case of concentrated heating, the heater occupies a small part of the active zone. Another paper presents calculations for the heat and mass transfer in the compensation chamber of the same evaporator and the intensity of internal heat exchange in the reservoir depending on its orientation [42]. The authors model heat and mass transfer processes in the entire evaporator/reservoir using the software $E F D . L a b^{2}$. They obtain the temperature field in

${ }^{2}$ EFD.Lab: a computational fluid dynamics formerly distributed by NIKA GmbH. The latest version, called FloEFD ${ }^{\mathrm{TM}}$, is distributed by Mentor Graphics ${ }^{\circledR}$
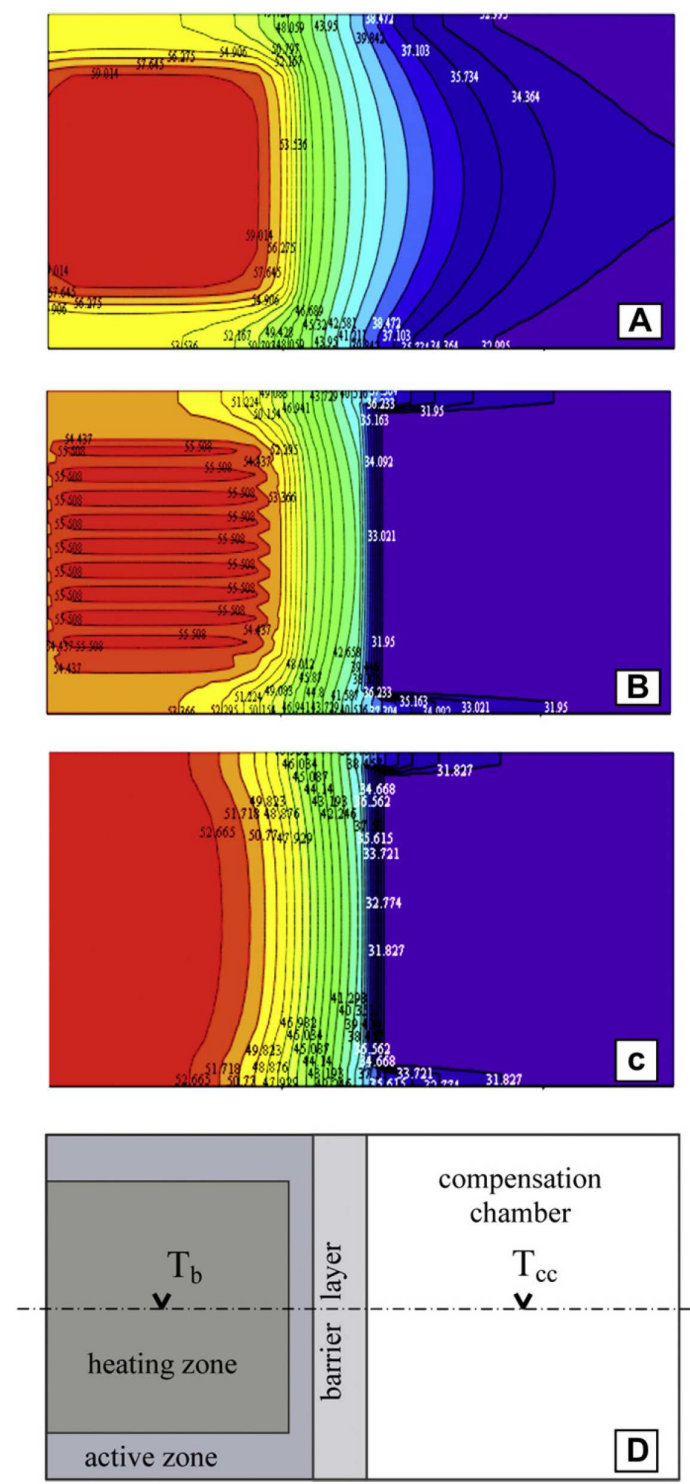

Figure 9: Temperature field with $Q_{\text {in }}=400 \mathrm{~W}$; A - top surface of the body, B - at level of half the groove depth, C - at level of half the evaporator thickness, D - evaporator view from above [40]

the evaporator and the velocity field in the compensation chamber. The latter is considered completely filled with liquid. A constant heat transfer coefficient with the ambient is assumed. A constant mass flow rate is taken into account for the entrance into the bayonet as well as for the interface between the wick and the liquid bulk. Furthermore, the surface of the vapour grooves is set at a constant temperature. The results show that the influence of the gravity is significant on heat and mass transfer in the reservoir. The local heat transfer coefficient in the liquid pool of the reservoir can reach $600 \mathrm{~W} \cdot \mathrm{m}^{-2} \cdot \mathrm{K}^{-1}$ close to the wick at high heat loads (Figure 10). The value of the mean heat exchange coefficient in the compensation chamber is about $140 \mathrm{~W} \cdot \mathrm{m}^{-2} \cdot \mathrm{K}^{-1}$ at high heat flux $\left(Q_{\text {in }}=500 \mathrm{~W}\right)$. 


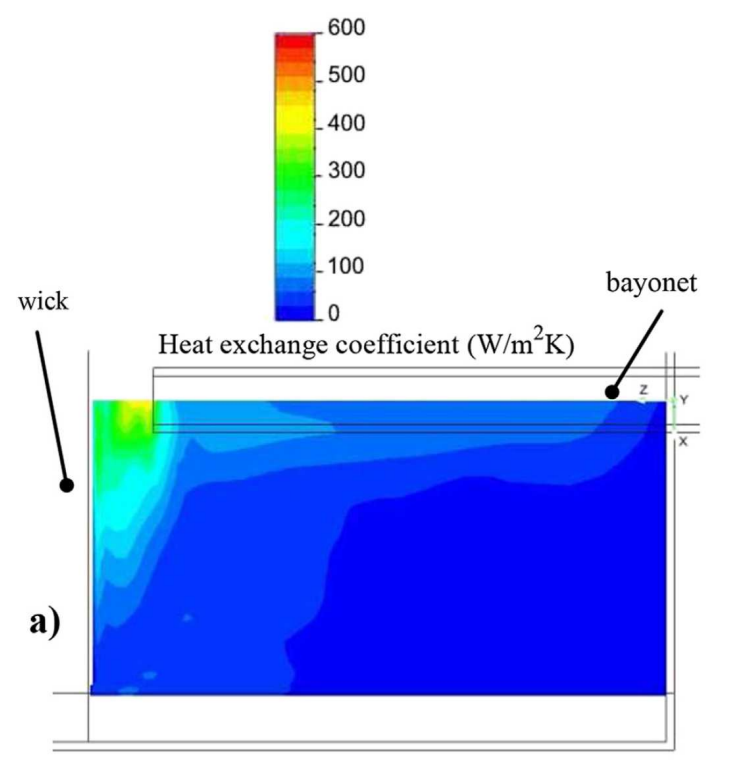

b)

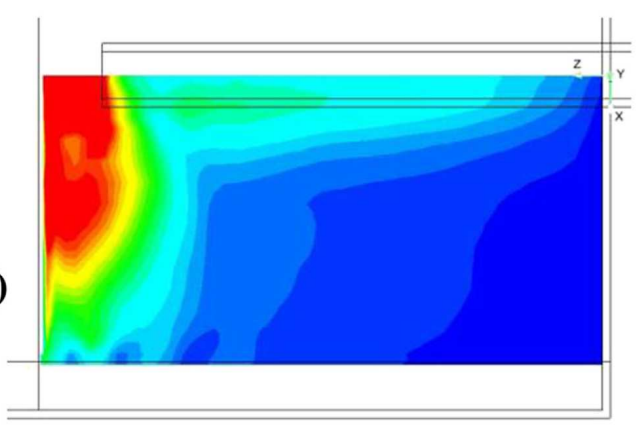

c)

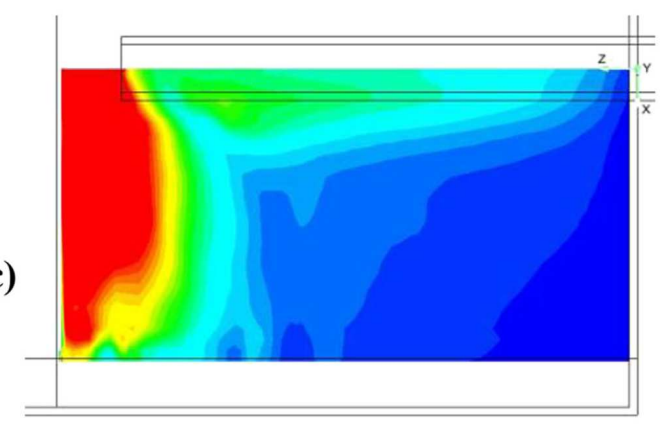

Figure 10: Heat transfer coefficient field at different heat loads: a) $100 \mathrm{~W}, \mathrm{~b}) 300 \mathrm{~W}$, c) $500 \mathrm{~W}[42]$

\subsection{Liquid-vapour interface in the wick}

The location of the liquid-vapour interface in the evaporator can have a significant influence on the heat transfer inside the wick and is mostly of interest when investigating the deprime of the loop following the drying out of the porous structure. Indeed, the growth of vapour zones inside the wick leads to a different thermal profile in the wick, to a change of the evaporation interface shape and, in case of a penetration across the entire porous structure, to a failure of the entire loop operation.

Considering heat and mass transfer and evaporation processes in conventional heat pipes, Demidov and Yatsenko [38] theoretically investigate the growth of a vapour zone inside the capillary structure. The authors postulate the existence of a vapour bubble between the wick and the fin, growing in size and eventually communicating with the groove (Figure 11).

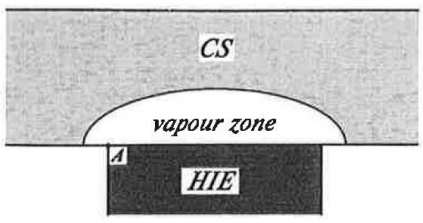

(a)

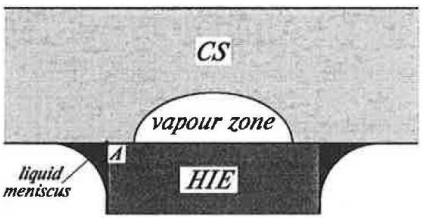

(b)
Figure 11: Growth of (a) a "large" vapour zone and (b) a "small" vapour zone inside the capillary structure [38]

This phenomenon is further studied by Figus et al. [31], who also develop a pore network model to consider a pore size distribution inside the porous structure. In this type of model, the pore space is modelled by a network of sites (pores) and bonds (throats), as presented in Figure 12. A complementary network is considered to take into account conductive heat transfer.

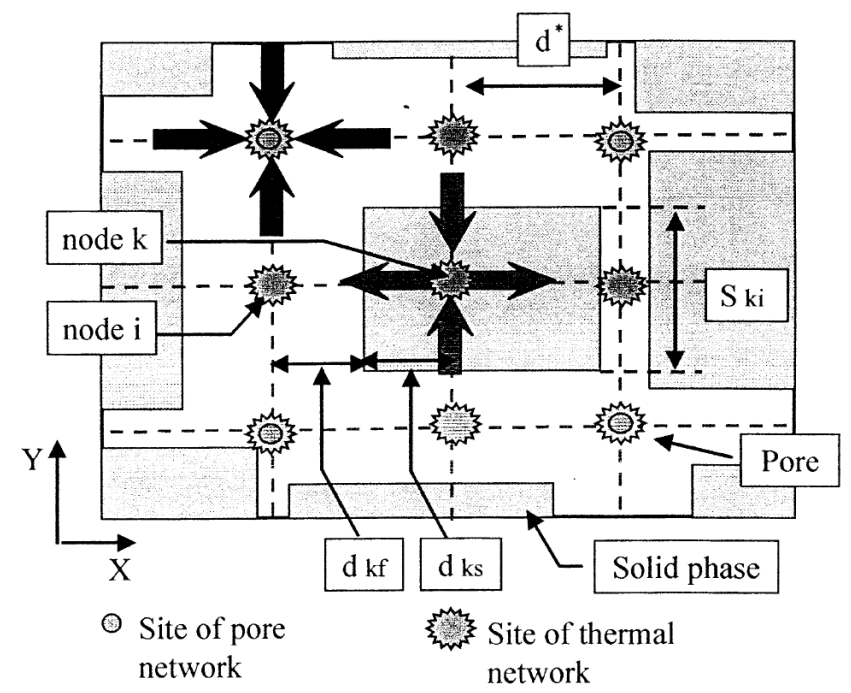

Figure 12: Sketch of a pore network model [31]

At the beginning of the numerical procedure, the network is saturated with liquid except the first series of bonds underneath the fin which are saturated with vapour. Mass, momentum and energy balance equations for each element of the networks enable the calculation of the temperature and the pressure fields. If the pressure difference across the liquid-vapour interface is higher than the maximal capillary pressure, the bond associated with that difference is invaded by the vapour. Once the network phase distribution has been updated, the overall procedure is repeated until a stationary solution is found.

The authors compare the standard continuum model (based on continuous equations) with the pore network one 
(Figure 13a), for a constant pore size in the entire wick. To locate the liquid-vapour interface inside the wick, the continuum model assumes the wick to be filled with vapour if its temperature is greater than the saturation temperature. Both methods give similar results characterised by a smooth vapour zone under the fin. When the wick does not have a homogeneous porosity, a fractal vapour zone extension is observed (Figure 13b). They obtain vapour breakthrough for heat flux equal to about $20 \mathrm{~W} \cdot \mathrm{cm}^{-2}$. As in the previously cited work, the authors assume the presence of an initial vapour zone in the wick, initiating the vapour invasion process.

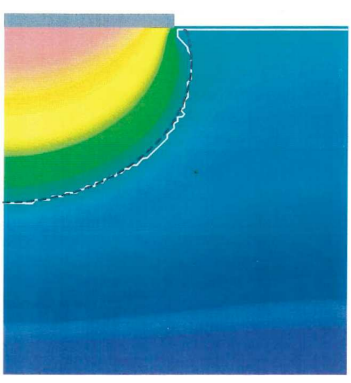

(a)
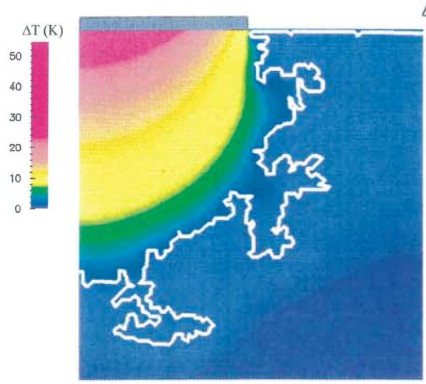

(b)
Figure 13: Pore-network simulations of the vapour front inside the porous wick [31]: (a) homogeneous porosity $\left(\phi=5 \mathrm{~kW} \cdot \mathrm{m}^{-2}\right)$ : continuum model (black) and pore-network model (white); (b) inhomogeneous porosity $\left(\phi=90 \mathrm{~kW} \cdot \mathrm{m}^{-2}\right)$

Other modelling works have been more recently published on this topic, further developing a pore network model. Coquard [32] improves the model of Figus et al. [31], considering convection in both the liquid and the vapour phases and taking into account the variation of the vapour density. Heat transfer in the grooves is calculated and the energy balance is also computed in the evaporator wall. Moreover, no symmetry is assumed for the vapour region. The author develops a dual model: the pressure and temperature fields are calculated using homogeneous equations whereas the capillarity and hence the location of the interface are considered using the pore network. To determine the incipience of the vapour development inside the porous structure, the author arbitrarily assumes a nucleation superheat of $3 \mathrm{~K}$. This assumption also implies the existence of vapour or gas embryos under the fin that facilitates the nucleation. According to the author, the presence of the vapour region inside the wick has a major influence on the evaporator operation. It induces an additional thermal resistance, leading to a large superheat of the fin and to an increase of the parasitic heat losses.

The model was further developed by Louriou [33] to take into account transient phenomena, which are not relevant to this review's topic.

Kaya and Goldak [34] numerically analyse heat and mass transfer in the porous structure of a loop heat pipe using a finite element method. They study the existence of a vapour region inside the wick to assess the boiling limit of LHPs. The authors expect nucleation to start in the microscopic cavities at the wick-fin interface for small superheat values as a result of trapped gas in these cavities. According to the authors, the boiling incipient superheat value is difficult to predict, since it depends on several parameters in a complex manner. Therefore, they arbitrarily assume the incipience of the vapour zone would occur if a superheat of $4 \mathrm{~K}$ of the liquid is reached. However, if the contact between the fin and the wick is improved and the working fluid is purified to the greatest possible extent, thus preventing the presence of vapour embryos trapped at the wick-fin interface, the boiling incipience can be delayed to higher superheats, at the same order of magnitude as that for homogeneous nucleation in a pure liquid. The authors investigate such a scenario, calculating the superheat limit using the cluster nucleation theory. Their experimental results indicate no strong transient effects that could be the expected consequence of an explosive evaporation at the wick-fin interface, even when the applied heat load is higher that the calculated boiling limit. They conclude that a vapour region must exist under the fin and provide an escape path for the bubbles to the groove, thus preventing a flash-like vapour expansion. However, the absence of strong transient effects does not necessarily confirms the partial drying of the capillary structure.

All of these numerical works assume initial clusters of non-condensable gases trapped between the wick and the fin. These clusters would enable the expansion of a vapour zone in the porous structure, requiring only a low superheat. In the case of a good mechanical contact between the wick and the evaporator body and if the purity of the working fluid is high, it can be assumed that no vapour nor gas would initially exist in the porous structure. The conditions of boiling initiation are then given by the homogeneous nucleation theory. In such a case, the boiling condition would be achieved at a very high superheat. As was explained by Mishkinis and Ochterbeck [43] and later confirmed by Kaya and Goldak [34], if the LHP is fabricated and filled with a high degree of carefulness, particularly for the degassing of the liquid and the elimination of non-condensable gases in the system, practically no boiling phenomenon is to be expected during operation.

\subsection{Conclusion}

All the previous described numerical analyses give a better understanding of the phenomena involved in the evaporator of a loop heat pipe. Parasitic heat transfer, heat exchange between the evaporator wall and the grooves, heat and mass transfer in the wick, in the vapour grooves and in the compensation chamber as well as the characterisation of the evaporation zone are investigated. These numerical studies show the complexity of heat and mass transfer in a loop evaporator and are a useful tool for improving the design and the manufacturing of LHPs. However, the operating parameters of the model (temperature of the liquid returning to the condenser, pressure difference between the 
groove and the reservoir) are either arbitrarily set or coupled with a very simplified loop model. Therefore, there is a lack of knowledge concerning the influence of the phenomena occurring in the evaporator on the entire system operation.

\section{Analytical studies on LHPs}

Following increasing computational resources, the major part of the modelling efforts focus on developing models using various numerical methods. Few research works present analytical models of LHPs, in which the operating parameters (temperature, pressure drops, mass flow rate, etc.) can be explicitly determined, without the need of any numerical scheme. However the analytical approach does not necessitate large numerical resources and can be easily implemented in a simple software. Therefore, it can be a powerful tool for the design and optimisation of loop heat pipes.

According to Launay et al. [44], Maydanik et al. [45] developed an analytical model with a closed-form solution based on an energy balance in the reservoir and the pressure balance in the overall loop. The radial parasitic heat transfer through the cylindrical wick was taken into account, but the axial heat flux and the heat losses to the ambient were neglected. Assuming low heat losses from the liquid line and a heat load equal to the heat dissipated by evaporation, the following simplified expression was given:

$$
T_{\mathrm{v}}=T_{\mathrm{c}, \mathrm{o}}+\left(T_{\mathrm{r}}-T_{\mathrm{c}, \mathrm{o}}\right)\left(\frac{D_{\mathrm{w}, \mathrm{o}}}{D_{\mathrm{w}, \mathrm{i}}}\right)^{\frac{Q_{\mathrm{in}} c_{\mathrm{p}, 1}}{2 \pi \lambda_{\mathrm{eff}} L_{\mathrm{w}} h_{\mathrm{lv}}}}
$$

where $T_{\mathrm{v}}, T_{\mathrm{r}}$ and $T_{\mathrm{c}, \mathrm{o}}$ are the temperatures in the vapour grooves, in the reservoir and at the end of the condenser, respectively. $D_{\mathrm{w}, \mathrm{o}}$ and $D_{\mathrm{w}, \mathrm{i}}$ are the outer and inner diameters of the wick, respectively and $L_{\mathrm{w}}$ its length. $\lambda_{\text {eff }}$ is the effective thermal conductivity of the wick. In this closedform solution, predicting the vapour temperature requires the knowledge of the temperatures at the condenser outlet and in the reservoir. Therefore, this expression cannot be directly used to express the LHP thermal operation based on its geometrical characteristics.

Cao and Faghri [46] present an analytical work for the heat and mass transfer in a rectangular capillary porous structure with partial heating and evaporation on the upper surface (Figure 14a). This geometry can be directly related to the evaporator of a CPL or an LHP. Based on symmetry assumptions, the authors use the method of separation of variables to determine solutions in the form of Fourier series. The sides of the computational domain are considered adiabatic, the bottom boundary condition is a set temperature and the upper boundary condition is a heat input on one side and a heat output on the other side. Therefore, analytical solutions for the liquid pressure, velocity and temperature fields in the porous structure are obtained (Figure 14).

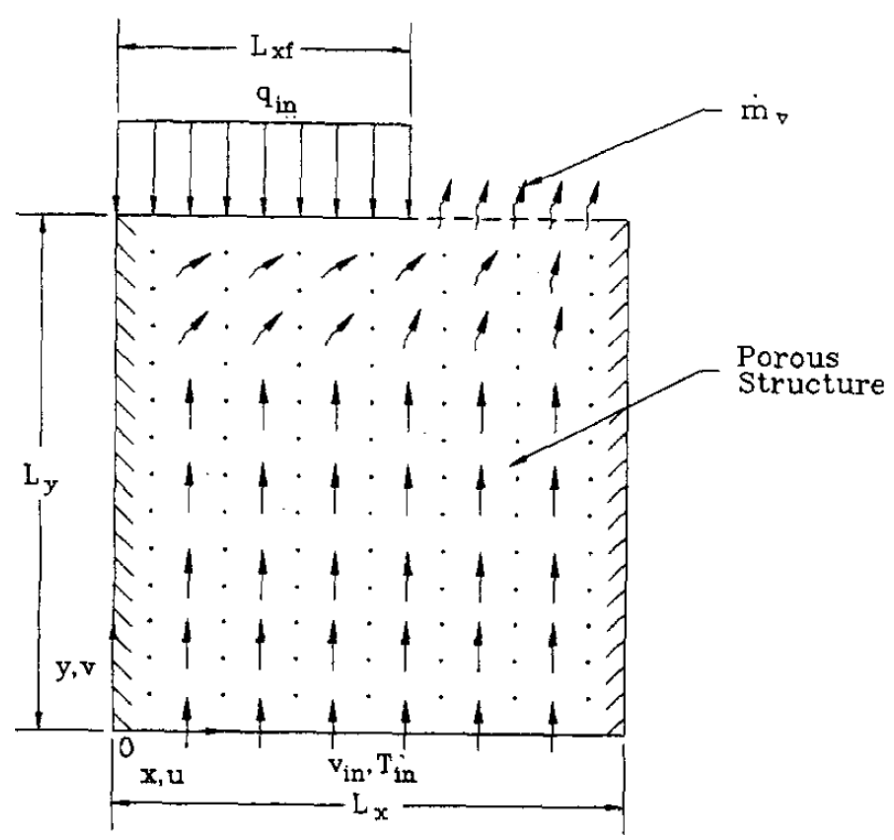

(a) Modelling domain

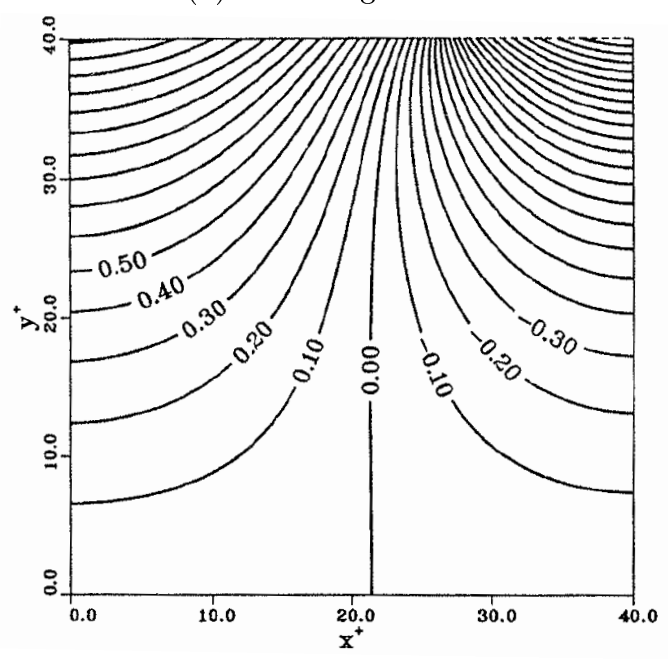

(b) Isotherms in the porous wick

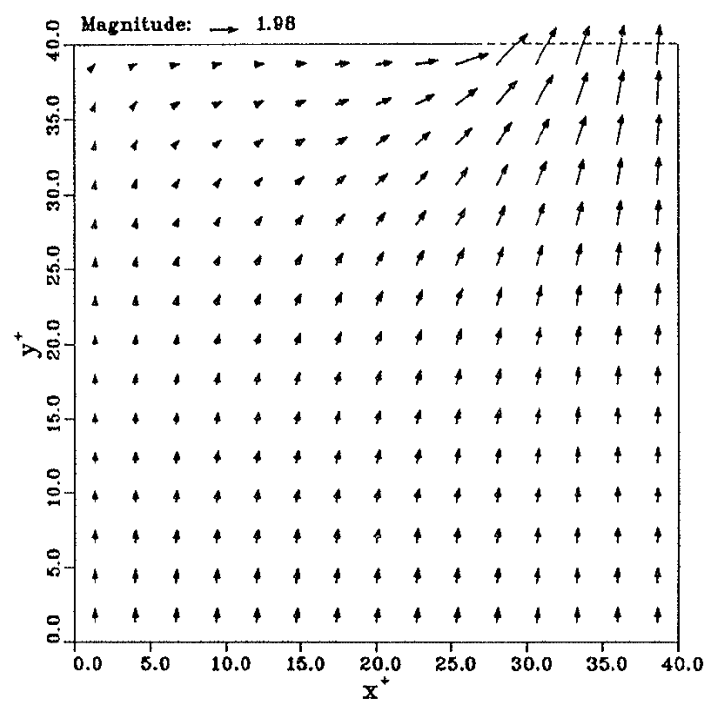

(c) Velocity vectors in the wick 
The results show the maximum temperature at the upper left-hand corner, under the fin. High temperature gradients are expected near the upper limit, whereas the temperature field is more uniform at the bottom. Concerning mass transfer, the liquid flows vertically into the porous structure and remains nearly one-dimensional until reaching the middle section of the wick.

Furukawa [47] presents a design-oriented analytical description of an LHP. His approach is very original and aims at optimising the design of the LHP in given operating conditions. The initial hypothesis is the knowledge of a design-specified operating temperature. The author solves the heat and mass transfer equations in the cylindrical evaporator. Pressure losses in the loop and heat transfer in the condenser are calculated as a function of the geometrical properties of the system. Several performance indices are defined (number of transfer units, temperature effectiveness, critical Bond number, pump efficiency) in order to improve the design of the LHP. Based on the operating temperature and on the geometrical and thermohydraulic characteristics of the loop, all the design parameters (wick thickness, transport lines diameter, wick pore radius and porosity, reservoir volume, condenser length) are evaluated. The paper presents several charts to optimise the design characteristics of the LHP. This study is a useful tool in the sizing of the LHP components based on temperature constraints. However, in many cases, the operating temperature is not necessarily the operating limit and is, as such, not a priori known.

Chernysheva et al. [24] present an analytical investigation of two compensation chamber operating modes, either the hard-filling or the two-phase state. Based on the thermodynamic relationship between the liquid-vapour interfaces in the groove and in the condenser or in the reservoir, the authors develop an analytical expression of the operating temperature $T_{\mathrm{ev}}$. In case of hard-filling, the evaporator temperature is equal to:

$$
\begin{aligned}
T_{\mathrm{ev}}= & T_{\text {sink }}+\left(\frac{1}{\alpha_{\text {cond,ext }} S_{\text {cond,ext }}}+R_{\text {cond,body }}\right. \\
& \left.+\frac{1}{\alpha_{\text {cond,int }} S_{\text {cond,int }}}+\sum_{i} W_{\mathrm{i}} F n_{\mathrm{i}}+\frac{1}{\alpha_{\mathrm{ev}} S_{\mathrm{q}}}\right) Q_{\text {load }}
\end{aligned}
$$

where $T_{\operatorname{sink}}$ is the heat sink temperature and $\alpha_{\text {cond,ext }}$, $\alpha_{\text {cond,int }}$ and $\alpha_{\text {ev }}$ are the heat transfer coefficient at the external side of the condenser, at the internal side of the condenser and in the evaporation zone, respectively. $S_{\text {cond,ext }}$ and $S_{\text {cond,int }}$ correspond to the external and internal surface areas of the condenser, respectively and $S_{\mathrm{q}}$ is the evaporator surface area where heat is supplied. $Q_{\text {load }}$ is the total heat load to be dissipated by the loop, $R_{\text {cond,body }}$ is the thermal resistance of the condenser wall and $W_{\mathbf{i}}$ and $F n_{\text {i }}$ are the coefficients taking into account the geometrical and thermophysical parameters in the calculation of pressure drops in the vapour line. In the case of an existing liquid-vapour interface inside the compensation chamber, the equation is modified to:

$$
T_{\mathrm{ev}}=T_{\mathrm{cc}}+\left.\left(\Delta P_{\mathrm{v}}+\Delta P_{1}+\Delta P_{\mathrm{g}}\right) \frac{\mathrm{d} T}{\mathrm{~d} P}\right|_{T}+\frac{Q_{\text {load }}}{\alpha_{\mathrm{ev}} S_{\mathrm{q}}}
$$

where $T_{\mathrm{cc}}$ is the temperature in the compensation chamber, and $\Delta P_{\mathrm{v}}, \Delta P_{1}$ and $\Delta P_{\mathrm{g}}$ are the pressure drops in the vapour line, in the liquid line, and due to the gravity, respectively. Despite providing a simple expression of the evaporator temperature, this development shows two main limitations. Firstly, in the case of a saturated reservoir, the operating temperature is a function of the compensation chamber temperature, which is a priori not known. Secondly, several major assumptions are made: heat losses to the ambient, parasitic heat transfer, two-phase pressure drops and heat transfer in the transport lines are neglected. Such hypotheses may lead to a large inaccuracy in the operation prediction.

Launay et al. [44] develop closed-form solutions linking the LHP operating temperature to various fluid properties and geometrical parameters. Based on an energy balance on each LHP component and on thermodynamic equations (Figure 15), the reservoir temperature $T_{\mathrm{r}}$ can be predicted for both the variable and the fixed conductance modes (Equation 18 and Equation 19). In these expressions, $K_{\mathrm{C}}$, $K_{\text {sub }}$ and $K_{\mathrm{L}}$ are global conductances defined in Figure 15 and $R_{\mathrm{E}}, R_{\mathrm{w}}$ and $R_{\mathrm{wall}}$ are evaporator resistances defined in the same figure. $L_{\mathrm{L}}$ and $L_{\mathrm{C}}$ are the lengths of the liquid line and of the condenser, respectively, and $D_{\mathrm{L}}$ and $D_{\mathrm{C}, \mathrm{i}}$ their respective diameters. $R_{\mathrm{A}}$ is the thermal resistance that represents heat losses of the reservoir to the ambient at temperature $T_{\mathrm{A}}$. Additionally, simple analytical solutions of the heat load corresponding to the transition between both modes are expressed. The effect of the geometrical parameters and fluid thermophysical properties on the LHP operation are clearly highlighted. However, the identification of the evaporator thermal resistance needs to be adjusted to experimental data or may require an additional evaporator accurate model.

This model is further developed by Siedel et al. [48]. The heat transfer equation in the evaporator/reservoir structure is solved using a Fourier series development. Therefore, the model combines both the advantages of a closedform solution with a precise determination of the parasitic heat fluxes.

Boo and Jung [49] conduct a theoretical modelling of a loop heat pipe with a flat evaporator. Based on a nodal network of the evaporator and of energy balance at each node of the system, the authors predict the temperatures of each component. The profile and the temperature of the liquid-vapour interface in the pores were expressed using the thin-film theory. The evaporation heat transfer coefficient is then dependent on the accommodation coefficient and on the heat conduction through the liquid film to the vapour. Transversal heat losses are also taken into account and a heat exchanger classical NTU method is used for the modelling of the condenser. However, no closedform solution of the operating temperature is given in the 


$$
\begin{aligned}
\mathrm{VCM} \quad T_{\mathrm{r}} & =\frac{T_{\text {sink }}+\frac{h_{\mathrm{lv}}}{c_{\mathrm{p}, 1}}\left[\frac{R_{\mathrm{E}}}{R_{\mathrm{wall}}}+\frac{T_{\mathrm{A}}}{R_{\mathrm{A}} Q_{\mathrm{in}}}\right]+\left(T_{\mathrm{A}}-T_{\text {sink }}\right)\left[1-\exp \left(-\frac{\pi D_{\mathrm{L}} L_{\mathrm{L}} K_{\mathrm{L}} h_{\mathrm{lv}}}{Q_{\text {in }} c_{\mathrm{p}, 1}}\right)\right]}{1-\frac{1}{Q_{\text {in }}}\left[\frac{1}{\rho_{\mathrm{v}} c_{\mathrm{p}, 1}}\left(\frac{1}{R_{\mathrm{w}}}+\frac{1}{R_{\text {wall }}}\right)\left(\Delta P_{\mathrm{v}}+\Delta P_{\mathrm{l}}-\Delta P_{\mathrm{g}}\right)-\frac{h_{\mathrm{lv}}}{c_{\mathrm{p}, 1} R_{\mathrm{A}}}\right]} \\
\mathrm{FCM} \quad T_{\mathrm{r}} & =T_{\text {sink }}+\frac{Q_{\text {in }}}{\pi D_{\mathrm{C}, \mathrm{i}} L_{\mathrm{C}} K_{\mathrm{C}}} \frac{1+\frac{R_{\mathrm{E}}}{R_{\mathrm{wall}}} \frac{K_{\mathrm{C}}}{K_{\text {sub }}}}{1+\frac{R_{\mathrm{E}}}{R_{\text {wall }}}}
\end{aligned}
$$

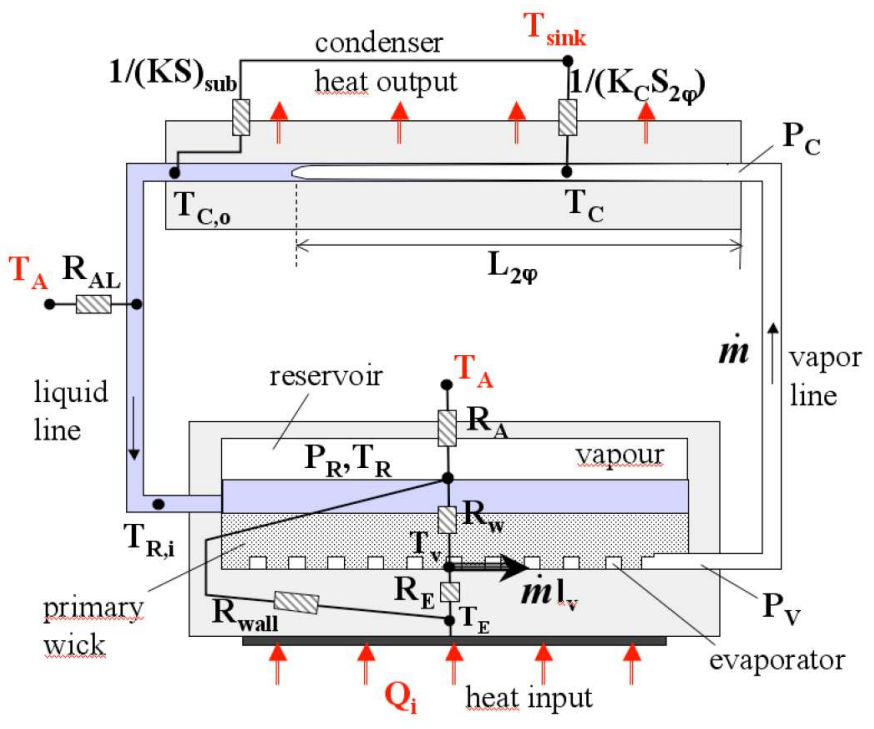

Figure 15: LHP thermal resistance network [44]

paper. Furthermore, longitudinal parasitic heat losses are not considered and the reservoir is assumed to be filled with liquid during operation, which does not necessarily correspond to an actual LHP operation.

\section{Conclusion}

The present review investigated the existing modelling studies of LHPs from the literature. Table 1 and Table 2 summarise the main steady-state modelling works of LHPs published in the past years. This survey considers both the complete models and the partial evaporator models. However, transient analyses were omitted, since they are not in the scope of the present study.

As presented in this paper, many theoretical works about LHPs have been undertaken in the past 15 years. Most of them are numerical analyses, based on nodal networks or on finite difference methods, whereas few analytical studies are developed. Specific codes for LHPs have been extensively developed in the past years, including more features and considering more accurately the physical phenomena involved in the loops. However, there are still only few studies that show a complete description of the LHP with a precise consideration of heat and mass transfer in the evaporator/reservoir structure, despite its major significance on the loop operation. This conclusion is a consequence of the complexity of the phenomena occurring in loop heat pipes.

This summary also shows the development of threedimensional models in the recent years, following the availability of larger computational resources. Flat evaporators have also been more investigated in the last years and show the gain of interest for this geometry of evaporator, as confirmed by Maydanik et al. [6]. The partial drying of the wick and the hard-filling are phenomena that have been seldom considered. However, most of the models investigate intensively heat and mass transfer in the transport lines and the condenser.

As explained in this paper, the literature presents an extensive number of steady-state models. These models are useful tools to predict the thermal performance of an LHP, to understand the coupled physical mechanisms involved in these systems, to estimate the influence of various parameters on the behaviour of LHPs and to improve their design. This diversity provides a large theoretical database for the community investigating loop heat pipes.

\section{References}

[1] Jentung $\mathrm{Ku}$. Operating characteristics of loop heat pipes. In $29^{\text {th }}$ International Conference on Environmental System, Denver, Colorado (USA), 1999.

[2] Yu.F. Maydanik. Loop heat pipes. Applied Thermal Engineering, 25:635-657, 2005.

[3] S. Launay, V. Sartre, and J. Bonjour. Parametric analysis of loop heat pipe operation: a literature review. International Journal of Thermal Sciences, 46(7):621-636, 2007.

[4] A. Ambirajan, A.A. Adoni, J.S. Vaidya, A.A. Rajendran, D. Kumar, and P. Dutta. Loop heat pipes: A review of fundamentals, operation, and design. Heat Transfer Engineering, 33 (4-5):387-405, 2012.

[5] Stéphane Launay and Martial Vallée. State-of-the-art experimental studies on loop heat pipes. Frontiers in Heat Pipes, 2 (1), 2011.

[6] Yu. F. Maydanik, M. A. Chernysheva, and V. G. Pastukhov. Review: Loop heat pipes with flat evaporators. Applied Thermal Engineering, 2014.

[7] Zhangyuan Wang and Wansheng Yang. A review on loop heat pipe for use in solar water heating. Energy and Buildings, 79: 143-154, August 2014.

[8] Tarik Kaya, Jentung Ku, Triem T. Hoang, and Mark K. Cheung. Mathematical modeling of loop heat pipes. In $3 \gamma^{t h} A I A A$ Aerospace Sciences Meeting and Exhibit, Reno, Nevada (USA), 1999. 
[9] D. Douglas, J. Ku, and T. Kaya. Testing of the geoscience laser altimeter system (GLAS) prototype loop heat pipe. In $37^{\text {th }}$ AIAA Aerospace Sciences Meeting and Exhibit, Reno, Nevada (USA), 1999. Goddard Space Flight Center, NASA. Paper 990473.

[10] Tarik Kaya and Jentung Ku. Thermal operational characteristics of a small-loop heat pipe. Journal of Thermophysics and Heat Transfer, 17(4):464-470, 2003.

[11] P.Y.A. Chuang. An improved steady-state model of loop heat pipes based on experimental and theoretical analyses. $\mathrm{PhD}$ thesis, Pennsylvania State University, 2003.

[12] A.A. Adoni, A. Ambirajan, VS Jasvanth, D. Kumar, P. Dutta, and K. Slinivasan. Thermohydraulic modeling of capillary pumped loop and loop heat pipe. Journal of Thermophysics and Heat Transfer, 21(2):410-421, 2007.

[13] J. El Hajal, J. R. Thome, and A. Cavallini. Condensation in horizontal tubes. part 1: two-phase flow pattern map. International Journal of Heat and Mass Transfer, 46(18):3349-3363, 2003.

[14] J. R. Thome, J. El Hajal, and A. Cavallini. Condensation in horizontal tubes. part 2: new heat transfer model based on flow regimes. International Journal of Heat and Mass Transfer, 46 (18):3365-3387, 2003.

[15] L. Friedel. Improved friction pressure drop correlations for horizontal and vertical two-phase pipe flow. In European Two-Phase Flow Group Meeting, volume 2, Ispra, Italy, 1979.

[16] Abhijit A. Adoni, Amrit Ambirajan, V. S. Jasvanth, Dinesh Kumar, and Pradip Dutta. Effects of mass of charge on loop heat pipe operational characteristics. Journal of Thermophysics and Heat Transfer, 23(2):346-355, 2009.

[17] A.A. Adoni, A. Ambirajan, VS Jasvanth, D. Kumar, and P. Dutta. Theoretical studies of hard filling in loop heat pipes. Journal of Thermophysics and Heat Transfer, 24(1):173-183, 2010.

[18] Lizhan Bai, Guiping Lin, Hongxing Zhang, and Dongsheng Wen. Mathematical modeling of steady-state operation of a loop heat pipe. Applied Thermal Engineering, 29:2643-2654, 2009.

[19] L. Bai, G. Lin, and D. Wen. Parametric analysis of steady-state operation of a CLHP. Applied Thermal Engineering, 30(8-9): $850-858,2010$.

[20] Randeep Singh, Aliakbar Akbarzadeh, Chris Dixon, and Masataka Mochizuki. Theoretical modelling of miniature loop heat pipe. Heat and Mass Transfer, 46(2):209-224, 2009.

[21] Nathanaël Rivière, Valérie Sartre, and Jocelyn Bonjour. Fluid mass distribution in a loop heat pipe with flat evaporator. In $15^{\text {th }}$ International Heat Pipe Conference, Clemson, South Carolina (USA), 2010.

[22] Benjamin Siedel, Valérie Sartre, and Frédéric Lefèvre. Numerical investigation of the thermohydraulic behaviour of a complete loop heat pipe. Applied Thermal Engineering, 61(2):541-553, 2013.

[23] R. Hodot, V. Sartre, F. Lefèvre, and C. Sarno. 3D modeling and optimization of a loop heat pipe evaporator. In $17^{\text {th }}$ International Heat Pipe Conference, Kanpur, India, 2013.

[24] M.A. Chernysheva, S.V. Vershinin, and Yu. F. Maydanik. Operating temperature and distribution of a working fluid in LHP. International Journal of Heat and Mass Transfer, 50:27042713, 2007.

[25] Brent Cullimore and Jane Baumann. Steady-state and transient loop heat pipe modeling. In $30^{\text {th }}$ International Conference on Environmental Systems, Toulouse, France, 2000.

[26] J. Kim and E. Golliher. Steady state model of a micro loop heat pipe. In $18^{\text {th }}$ Annual IEEE Symposium, Semiconductor Thermal Measurement and Management, pages 137-144, San Jose, California (USA), 2002.

[27] Mohammed Hamdan, Frank M. Gerner, and H. T. Henderson. Steady state model of a loop heat pipe (LHP) with coherent porous silicon (CPS) wick in the evaporator. In $19^{\text {th }}$ Annual IEEE Symposium, Semiconductor Thermal Measurement and Management, pages 88-96, San Jose, California (USA), 2003.
[28] M. Ghajar, J. Darabi, and N Crews Jr. A hybrid CFDmathematical model for simulation of a MEMS loop heat pipe for electronics cooling applications. Journal of Micromechanics and Microengineering, 15:313-321, 2005.

[29] Yun-Ze Li, Yu-Ying Wang, and Kok-Meng Lee. Dynamic modeling and transient performance analysis of a LHP-MEMS thermal management system for spacecraft electronics. IEEE Transactions on Components and Packaging Technologies, 33(3): 597-606, 2010.

[30] Mohammad Hamdan and Emad Elnajjar. Thermodynamic analytical model of a loop heat pipe. Heat and Mass Transfer, 46 (2):167-173, 2009 .

[31] C. Figus, Y. Le Bray, S. Bories, and Marc Prat. Heat and mass transfer with phase change in a porous structure partially heated: continuum model and pore network simulations. International Journal of Heat and Mass Transfer, 42:1446-1458, 1999.

[32] Typhaine Coquard. Transferts couplés de masse et de chaleur dans un élément d'évaporateur capillaire. $\mathrm{PhD}$ thesis, Institut National Polytechnique de Toulouse, 2006.

[33] Clément Louriou. Modélisation instationnaire des transferts de masse et de chaleur au sein des évaporateurs capillaires. PhD thesis, Institut National Polytechnique de Toulouse, 2010.

[34] Tarik Kaya and John Goldak. Numerical analysis of heat and mass transfer in the capillary structure of a loop heat pipe. International Journal of Heat and Mass Transfer, 49:3211-3220, 2006.

[35] T.S Zhao and Q Liao. On capillary-driven flow and phasechange heat transfer in a porous structure heated by a finned surface: measurements and modeling. International Journal of Heat and Mass Transfer, 43(7):1141-1155, 2000.

[36] MA Chernysheva and Y.F. Maydanik. Heat and mass transfer in evaporator of loop heat pipe. Journal of Thermophysics and Heat Transfer, 23(4):725-731, 2009.

[37] J. Li and GP Peterson. 3D heat transfer analysis in a loop heat pipe evaporator with a fully saturated wick. International Journal of Heat and Mass Transfer, 54(1):564-574, 2011.

[38] A.S. Demidov and E.S. Yatsenko. Investigation of heat and mass transfer in the evaporation zone of a heat pipe operating by the ' inverted meniscus' principle. International Journal of Heat and Mass Transfer, 37(14):2155-2163, 1994.

[39] Xianfeng Zhang, Xuanyou Li, and Shuangfeng Wang. Threedimensional simulation on heat transfer in the flat evaporator of miniature loop heat pipe. International Journal of Thermal Sciences, 54:188-198, 2012.

[40] Mariya A. Chernysheva and Yury F. Maydanik. 3D-model for heat and mass transfer simulation in flat evaporator of copperwater loop heat pipe. Applied Thermal Engineering, 33-34:124$134,2012$.

[41] Mariya A. Chernysheva and Yury F. Maydanik. Simulation of thermal processes in a flat evaporator of a copper-water loop heat pipe under uniform and concentrated heating. International Journal of Heat and Mass Transfer, 55(25-26):73857397, 2012.

[42] Mariya A. Chernysheva, Vladimir G. Pastukhov, and Yury F. Maydanik. Analysis of heat exchange in the compensation chamber of a loop heat pipe. Energy, 55:253-262, 2013.

[43] D. Mishkinis and JM Ochterbeck. Homogeneous nucleation and the heat-pipe boiling limitation. Journal of Engineering Physics and Thermophysics, 76(4):813-818, 2003.

[44] S. Launay, V. Sartre, and J. Bonjour. Analytical model for characterization of loop heat pipes. Journal of Thermophysics and Heat Transfer, 22(4):623-631, 2008.

[45] Yury F. Maydanik, Yury G. Fershtater, and Nikolay N. Solodovnik. Loop heat pipes: Design, investigation, prospects of use in aerospace technics. Technical Report 941185, SAE International, Warrendale, PA, 1994.

[46] Y. Cao and A. Faghri. Analytical solutions of flow and heat transfer in a porous structure with partial heating and evaporation on the upper surface. International Journal of Heat and Mass Transfer, 37(10):1525-1533, 1994. 
[47] M. Furukawa. Model-based method of theoretical design analysis of a loop heat pipe. Journal of Thermophysics and Heat Transfer, 20(1):111-121, 2006.

[48] Benjamin Siedel, Valérie Sartre, and Frédéric Lefevre. Steadystate analytical model of a loop heat pipe. In $17^{\text {th }}$ International Heat Pipe Conference, Kanpur, India, 2013.

[49] Joon Hong Boo and Eui Guk Jung. A theoretical modeling of a loop heat pipe with a flat evaporator employing the thin-film theory. In $15^{\text {th }}$ International Heat Pipe Conference, Clemson, South Carolina (USA), 2010.

[50] A.A.M. Delil, V. Baturkin, G. Gorbenko, P. Gakal, and V. Ruzaykin. Modelling of a miniature loop heat pipe with a flat evaporator. In Proceedings of the $32^{\text {nd }}$ International Conference on Environmental Systems, 2002.

[51] Mohammed Hamdan. Loop heat pipe (LHP) modeling and development by utilizing coherent porous silicon (CPS) wicks. PhD thesis, University of Cincinnati, 2003.

[52] Triem T. Hoang and Jentung $\mathrm{Ku}$. Heat and mass transfer in loop heat pipes. In ASME Summer Heat Transfer Conference, pages 485-493, Las Vegas, Nevada (USA), 2003.

[53] Triem T. Hoang, Tamara O'Connell, and Jentung Ku. Mathematical modeling of loop heat pipes with multiple capillary pumps and multiple condensers, Part I - steady state simulations. In $2^{\text {nd }}$ International Energy Conversion Engineering Conference, AIAA Paper 2004-5577, Providence, Rhode Island (USA), 2004.

[54] Nima Atabaki. Experimental and computational studies of loop heat pipes. $\mathrm{PhD}$ thesis, McGill University, Montréal, Québec, Canada, 2006.

[55] Nirmalakanth Jesuthasan. Modeling of Thermofluid Phenomena in Segmented Network Simulations of Loop Heat Pipes. PhD thesis, McGill University, Montréal, Québec, Canada, 2011.

[56] Fang-Chou Lin, Bing-Han Liu, Chi-Ting Huang, and Yau-Ming Chen. Evaporative heat transfer model of a loop heat pipe with bidisperse wick structure. International Journal of Heat and Mass Transfer, 54(21-22):4621-4629, 2011.

[57] Masakazu Kuroi and Hosei Nagano. The influence of groove shape on loop heat pipes' performance. In $16^{\text {th }}$ International Heat Pipe Conference, Lyon, France, 2012.

[58] Lizhan Bai, Guiping Lin, Zuodong $\mathrm{Mu}$, and Dongsheng Wen. Theoretical analysis of steady-state performance of a loop heat pipe with a novel evaporator. Applied Thermal Engineering, 64 (1-2):233-241, 2014.

[59] Tao Fang, Tingzhen Ming, C. P. Tso, Xiaoming Huang, and Wei Liu. Analysis of non-uniform heat loads on evaporators with loop heat pipes. International Journal of Heat and Mass Transfer, 75:313-326, 2014.

[60] Masataka Mitomi and Hosei Nagano. Long-distance loop heat pipe for effective utilization of energy. International Journal of Heat and Mass Transfer, 77:777-784, 2014. 


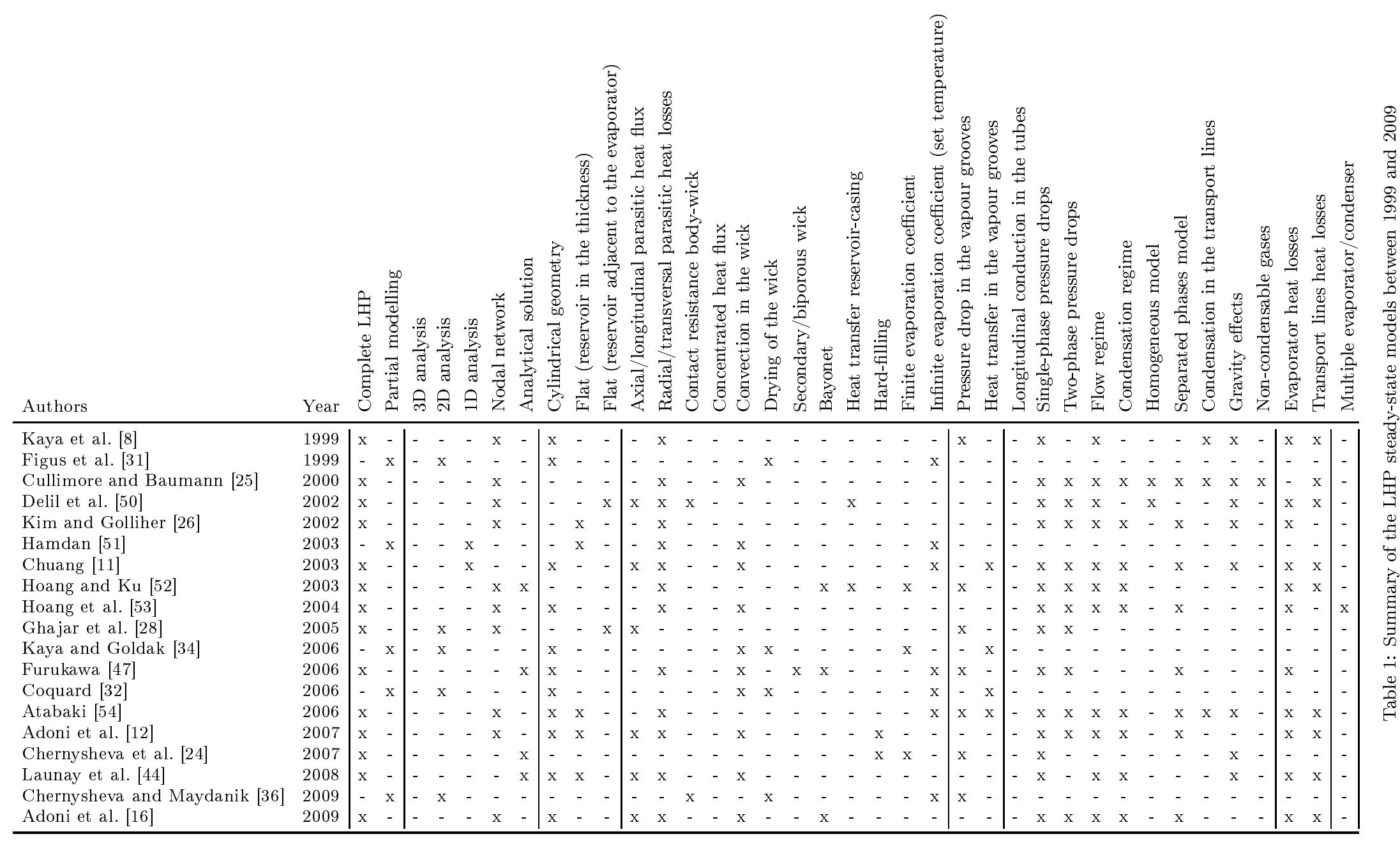




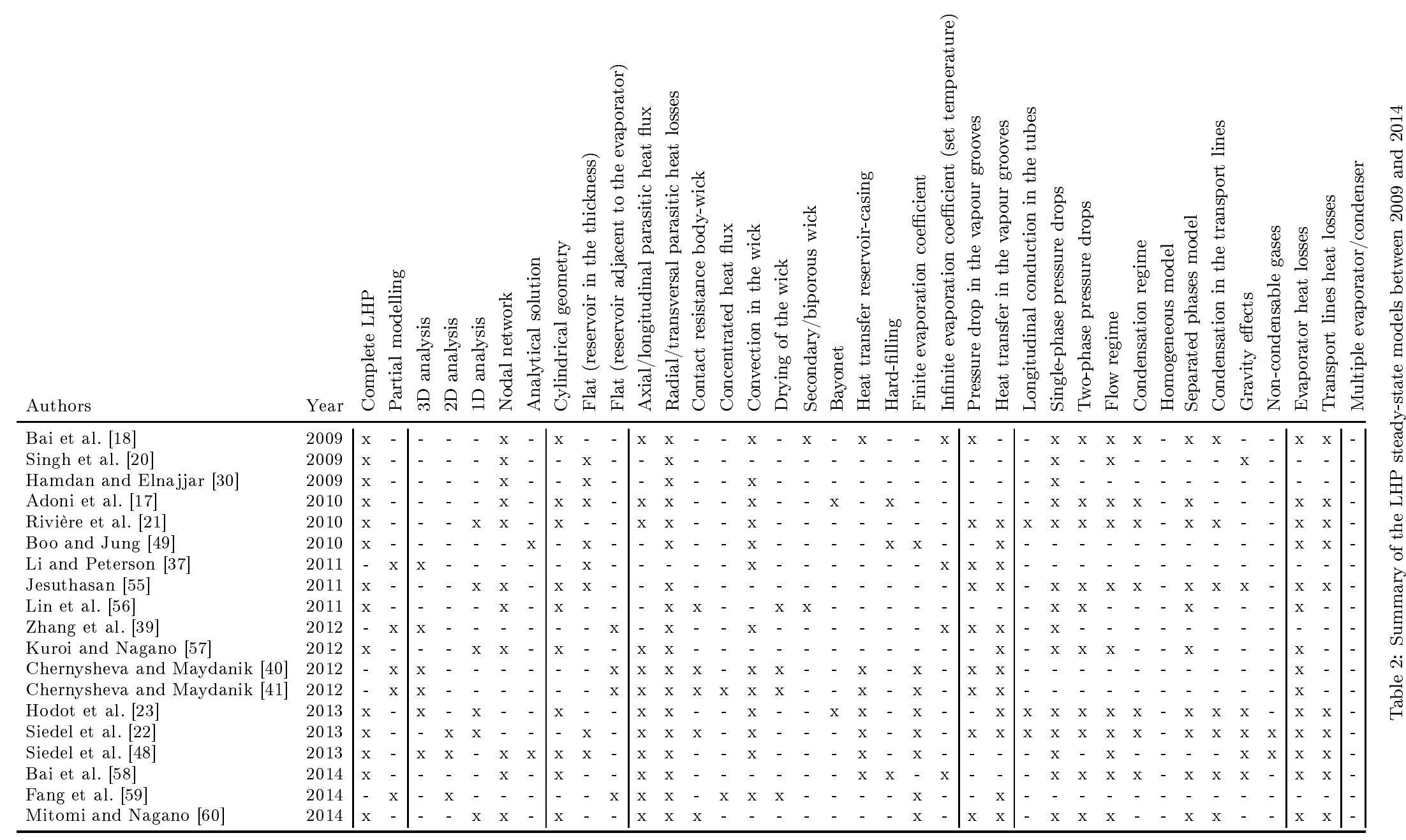

